\title{
Population under a Cap on Greenhouse Gas Emissions
}

\author{
Henning Bohn \\ Charles Stuart
}

CESIFO WORKING PAPER No. 3046

CATEGORY 1: PUBLIC FinANCE

MAY 2010

\footnotetext{
An electronic version of the paper may be downloaded

- from the SSRN website: www.SSRN.com

- from the RePEc website: - from the CESifo website: 


\title{
Population under a Cap on Greenhouse Gas Emissions
}

\begin{abstract}
A cap on greenhouse gas emissions makes total emissions a fixed common-property resource. Population increases under a cap are therefore self-limiting: a population increase raises labor and reduces emissions per unit of labor, which lowers incomes and fertility. Because a marginal birth under a cap lowers all incomes, a cap induces a negative population externality. The externality is substantial in calibrations, about 20 percent of income in steady state and 5 percent of income immediately after imposition, or more, per child. Similarly, the optimal population may be one-quarter of the natural population in steady state.
\end{abstract}

JEL-Code: H21, H23, O40, Q56.

Keywords: population externality, Pigovian tax, emissions cap, endogenous fertility, economic growth, optimal population, calibrated optimal child tax.

Henning Bohn

Department of Economics

University of California, Santa Barbara USA

bohn@econ.ucsb.edu
Charles Stuart

Department of Economics

University of California, Santa Barbara USA

stuart@econ.ucsb.edu

April 30, 2010 
The Kyoto Protocol lays the groundwork for a system of caps on greenhouse gas emissions. Emissions caps have been put in place in the EU and have been proposed for the U.S. and other countries. We show that imposition of an emissions cap bounds an economy's population and induces a negative population externality that is large under reasonable assumptions.

These results arise because the level of total emissions is a fixed commonproperty resource under a binding cap. (Without a cap, the global environment may be a fixed common-property resource but the level of total emissions is not.) Total emissions are constant when a cap binds and equal per-capita emissions times population, so a rise in population reduces per-capita emissions. Lower per-capita emissions in turn act to lower incomes and hence fertility. Thus population increases under a cap are self-limiting.

Because a rise in population under a cap reduces incomes for everyone, the rise generates a negative externality. A consequence is that the optimal population, meaning the population that would be set by a social planner taking account of the externality, is lower than the natural population, meaning the population that would arise absent any policy-induced net incentive to have children.

We study the natural and optimal populations in a balanced-growth setting in which output is produced using inputs of labor and greenhouse gas emissions. Emissions are free until a cap is imposed. Population and hence labor are determined endogenously from the optimal fertility in a Barro-Becker (1988, 1989) dynastic household model. The setting can describe either a national economy with a cap imposed under an international agreement or the whole world under a global cap.

Before a cap is imposed, population grows at a constant, positive rate. If there is no productivity growth, a cap causes fertility to fall to replacement as population converges to a steady-state constant. This "Malthusian" outcome is modified if productivity grows exogenously: the economy instead converges to a steady state in which the natural and optimal populations rise with a growth factor (one plus the growth rate) equal to the growth factor for emissions productivity divided by the growth factor for labor productivity. Under reasonable assumptions, this means that the natural and optimal populations fall over time.

We calculate the optimal population sequence and the corresponding sequence of optimal taxes on having a child (optimal child taxes). These are Pigovian taxes that measure the overall policy incentives needed to get households voluntarily to choose the optimal population. ${ }^{1}$

Calibrated optimal child taxes are large and thus at odds with tax, welfare, and schooling policies that subsidize costs of having children. Large optimal child taxes are also at odds with calls to encourage population growth in order to maintain the solvency of social security.

\footnotetext{
${ }^{1}$ Harford (1998) shows that the optimal child tax equals the present value of the externalities the child and the child's offspring will generate. The optimal taxes in our model have this property.
} 
The analysis describes general effects of any cap and requires no assumptions about how or even whether emissions damage the environment. An assessment of underlying damages would be needed to determine the optimal level of a cap, but this is beyond the scope of the current paper. ${ }^{2}$ The analysis also assumes an emissions cap is the only source of a population externality: there are no positive human-capital externalities and no negative congestion externalities.

We first lay out theoretical issues in a relatively minimal setting. Section I describes the setting. Section II describes the natural population before a cap is imposed. Section III describes the natural population under a cap. Section IV describes the optimal population and optimal child taxes under a cap. Section $\mathrm{V}$ shows that the population externality arises because of imperfect property rights. In section VI, we extend the model to set the stage for calibrations by adding time costs of children, a more general technology, and exogenously-given productivity growth. Section VII contains calibrations. Proofs and derivations are in an appendix at http://www.econ.ucsb.edu/ ${ }^{\sim}$ bohn/papers/CCapp.pdf.

\section{Setting}

Denote the time- $t$ adult population by $N_{t}$ and aggregate labor by $L_{t}=l_{t} N_{t}$ where $l_{t}$ is per-capita labor. (Throughout, per-capita means per-adult.) A representative firm operating under perfect competition produces output $Y_{t}$ from labor and $E_{t}$ units of greenhouse gas emissions according to

$$
Y_{t}=F\left(L_{t}, E_{t}\right),
$$

which is increasing, strictly concave, and exhibits constant returns. ${ }^{3}$ We abstract from capital and other inputs. We also abstract from productivity growth until section VI, where we show the analysis holds with exogenously growing productivity if growing variables are deflated in the standard way with growth factors.

Constant returns implies that (1) can be written

$$
Y_{t}=L_{t} f\left(e_{t}\right)
$$

where $e_{t} \equiv E_{t} / L_{t}$ is the ratio of emissions to labor (compactly, the emissions ratio) and $f$ is output per unit of labor.

\footnotetext{
${ }^{2}$ Integrated assessment models (e.g. Mendelsohn et al. 1998, Nordhaus and Boyer 2000) have been used to calculate damages. Adding the damage assumptions of these models to the current analysis would mean adding environmental state variables and using both population and emissions (cap) levels as controls. Adding damage assumptions would also cloud analysis of a cap with assumptions needed to calculate damages. For instance, damages can vary greatly depending on how one treats "catastrophic" losses that may be difficult to quantify.

Note that Kelly and Kolstad (2001) use an integrated assessment model to calculate the welfare cost of a marginal child. Their calculated cost is tiny compared with results here.

${ }^{3}$ Implicit in (1) is that past emissions do not reduce current output. This simplifies the analysis and highlights that imposition of a cap alone suffices to induce a population externality.
} 
Emissions are free before a cap is imposed so we assume there is a positive value $e^{+}<\infty$ at which emissions have zero marginal product, $f^{\prime}\left(e^{+}\right)=0$, with $f^{\prime}\left(e_{t}\right)>0$ for $0 \leq e_{t}<e^{+}$. For now, we assume emissions are an essential input in that $f(0)=0$; this is relaxed in section VI where we study a "backstop" technology that allows output to be positive with zero emissions.

The story is that population and total greenhouse gas emissions grow unhindered over time until a transition period indexed $t=0$ when emissions are first recognized to be an issue. Starting at $t=0$, government imposes a cap by creating and auctioning $\hat{E}$ permits in each period, each permit allowing one unit of emissions in the period so $E_{t} \leq \hat{E}<\infty$ for $t \geq 0$. Prior to period zero there is no expectation of any cap; for $t \geq 0$, there is perfect foresight that a perfectly enforced cap is fixed at $\hat{E} .{ }^{4}$ We treat permits as valid for a single period because actual and proposed caps do not have the character of permanent property rights. The recent Kerry-Boxer bill, for instance, explicitly states that permits are not property rights and that nothing restricts future government from terminating or limiting an emission allowance.

In the market for emissions permits, the government is the supplier and the representative firm is the demander. The firm maximizes profits $L_{t} f\left(e_{t}\right)-$ $p_{t} E_{t}-w_{t} L_{t}$, where $p_{t}$ is the price of permits and $w_{t}$ is the wage. The first-order conditions are $p_{t}=f^{\prime}\left(e_{t}\right)$ and $w_{t}=w\left(e_{t}\right) \equiv f\left(e_{t}\right)-e_{t} f^{\prime}\left(e_{t}\right)$.

The quantity of permits demanded at $p_{t}=0$ is $e^{+} L_{t}$. If $e^{+} L_{t}<\hat{E}$, the cap does not bind, $p_{t}=0$, and $e_{t}=e^{+}$. If $e^{+} L_{t}>\hat{E}$, the cap binds, $p_{t}>0$, and $e_{t}=\hat{E} / L_{t}<e^{+}$. (If $e^{+} L_{t}=\hat{E}$, then $p_{t}=0$ and $e_{t}=e^{+}$.) Thus the emissions ratio is $e\left(L_{t}\right) \equiv \min \left(e^{+}, \hat{E} / L_{t}\right)$ for any $L_{t}$.

Because $L_{t}=l_{t} N_{t}$, a cap means the emissions ratio depends on population:

$$
e_{t}=e\left(l_{t} N_{t}\right)=\min \left(e^{+}, \frac{\hat{E}}{l_{t} N_{t}}\right) .
$$

To highlight the dependence simply, we assume for now that per-capita labor is fixed and normalized to one. When $l_{t}=1$, labor equals the adult population, per-capita emissions equal the emissions ratio $e\left(N_{t}\right)$, and per-capita output equals $f\left(e\left(N_{t}\right)\right)$. In section VI, we generalize by assuming that children also require parental time, which reduces labor supply.

Population in turn depends on fertility $n_{t} \geq 0$. A large number of representative dynastic households each contain a single adult who chooses $n_{t}$ to maximize utility; $n_{t}$ is not restricted to integers. When all households choose $n_{t}$, the adult population evolves as $N_{t+1}=n_{t} N_{t}$.

We follow Barro and Becker's (1988) specification of household preferences. A period- $t$ adult's utility $U_{t}$ is the sum of utility $u$ from own consumption $c_{t} \geq 0$,

\footnotetext{
${ }^{4}$ A fixed cap abstracts from changes in emission rights that might result from improved understanding of how emissions affect climate. Kelly and Kolstad (1999) estimate that natural temperature fluctuations mean it may take 90-160 years to resolve uncertainty about how greenhouse gases affect climate.
} 
plus utility from children:

$$
U_{t}=u\left(c_{t}\right)+\beta\left(n_{t}\right) U_{t+1},
$$

where children are identical and utility from children is the utility of a child times a weight $\beta$ that depends on the number of children.

We assume power utility with parameter $\theta>0$ :

$$
u(c)=\frac{1}{1-\theta} c^{1-\theta}
$$

the power form is needed later to allow for balanced growth. We also assume that $\beta$ is a power function with parameters $b_{0}>0$ and $b>0$ :

$$
\beta(n)=b_{0} n^{1-b},
$$

which is equivalent to assuming the utility an adult derives from grandchildren is independent of the number of children. ${ }^{5}$

In Barro and Becker's original specification, $u$ was restricted to be positive, which requires $\theta<1$, and $\beta$ was restricted to be increasing and concave. Together these ensure that parental utility rises at a decreasing rate with the number of children. Jones and Schoonbroodt (2007) and Jones et al (2008) have shown that parental utility also rises at a decreasing rate with the number of children if $\theta>1$ as long as $\beta$ is decreasing and convex; they argue this case may better explain historical fertility trends. We therefore consider two cases: a Barro-Becker case with $\theta<1$ and $b<1$, so $u>0, \beta^{\prime}>0$, and $\beta^{\prime \prime}<0$; and a Jones-Schoonbroodt case with $\theta>1$ and $b>1$, so $u<0, \beta^{\prime}<0$, and $\beta^{\prime \prime}>0$. In both cases, $u^{\prime}>0$ and $u^{\prime \prime}<0$.

An adult's consumption is per-capita income, $y_{t}$, less the output cost of having and raising children to reproductive age:

$$
c_{t}=y_{t}-\chi n_{t},
$$

where $\chi$ is the output cost of a child. Maximum feasible fertility is $f\left(e^{+}\right) / \chi$, which is maximum per-capita output divided by the cost of a child. ${ }^{6}$

We close the model by assuming the government simply redistributes revenue from emissions auctions as equal lump sums to households. ${ }^{7}$ Per-capita income

\footnotetext{
${ }^{5}$ Utility from grandchildren is $\beta\left(n_{t}\right) \beta\left(n_{t+1}\right) U_{t+2}$. Independence implies $\beta\left(n_{t}\right) \beta\left(n_{t+1}\right)=$ $\beta(1) \beta\left(n_{t} n_{t+1}\right)$. Differentiating this with respect to $n_{t}$ and $n_{t+1}$ yields $n_{t} \beta^{\prime}\left(n_{t}\right) / \beta\left(n_{t}\right)=$ $n_{t+1} \beta^{\prime}\left(n_{t+1}\right) / \beta\left(n_{t+1}\right)$ for any $n_{t}>0$ and $n_{t+1}>0$, so $n \beta^{\prime}(n) / \beta(n)$ is a constant, denoted $1-b$. The solution to the differential equation $\beta^{\prime}(n) / \beta(n)=(1-b) / n$ is $\beta(n)=b_{0} n^{1-b}$. Conversely, $\beta\left(n_{t}\right)=b_{0} n_{t}^{1-b}$ implies $\beta\left(n_{t}\right) \beta\left(n_{t+1}\right)=b_{0} n_{t}^{1-b} b_{0} n_{t+1}^{1-b}=\beta(1) \beta\left(n_{t} n_{t+1}\right)$.

${ }^{6}$ Utility (4) is infinite if the discount factors given by $\beta$ are too great. In the Barro-Becker case, $\beta$ rises with fertility. We therefore assume $\beta<1$ at the maximum feasible fertility in the Barro-Becker case to ensure $\beta(n)<1$ for any feasible $n$, so utility is finite. In the JonesSchoonbroodt case, $\beta$ is infinite at $n=0$ and falls with $n$. In this case we assume $b_{0}<1$, which implies there is an $n^{\circ}<1$ at which $\beta\left(n^{\circ}\right)=1$ with $\beta(n)<1$ for all $n>n^{\circ}$, so utility is finite on paths with constant population.

${ }^{7}$ This abstract from optimal-tax issues caused by public goods and distortionary taxes. Optimal-tax issues may be important if auction revenue is large, as calibrations below suggest, or if interactions between environmental policy and distortionary taxes are large-see e.g. Bovenberg and Goulder (1996).
} 
is therefore wages plus transfers, $T R_{t}=p_{t} E_{t} / N_{t}=p_{t} e_{t}$. From the firm's firstorder conditions, per-capita income equals output per unit of labor:

$$
y_{t}=w_{t}+p_{t} e_{t}=f\left(e_{t}\right) .
$$

The policy of auctioning emissions permits and redistributing the revenue to households is equivalent in the setting here to a policy of issuing and giving permits to households who then sell them at price $p_{t}$, and is also equivalent to a policy of issuing and giving permits to firms owned by households. A permit auction with redistribution is also equivalent to a policy of imposing a tax on emissions at rate $f^{\prime}$, which would just hold total emissions to $\hat{E}$, and redistributing the revenue to households. In this way, an emissions cap is equivalent here to a tax on emissions; both a cap and a tax reduce $e_{t}$ and hence individual income.

For use below, the factor share of emissions permits is $\frac{p_{t} e_{t}}{w_{t}+p_{t} e_{t}}=\frac{f^{\prime}\left(e_{t}\right) e_{t}}{f_{t}}$, which is fully determined by $f$. This factor share is zero at $e^{+}$and becomes positive as $e$ falls below $e^{+}$.

\section{A. Fertility Choice}

In choosing fertility, a household takes its income as well as the incomes and fertilities of future generations as given. The latter determine the utility of children. Generically (dropping time subscripts), the household maximizes

$$
V(n, y, U) \equiv u(y-\chi n)+\beta(n) U
$$

by choice of $n \in[0, y / \chi]$ given $y>0$ and finite $U$, where $U>0$ in the BarroBecker case and $U<0$ in the Jones-Schoonbroodt case.

The first-order condition balances the costs and benefits of children:

$$
V_{n}(n, y, U) \equiv-u^{\prime} \chi+\beta^{\prime} U=0 .
$$

The second-order condition, $V_{n n}=u^{\prime \prime} \chi^{2}+\beta^{\prime \prime} U<0$, holds by assumptions on primitives.

Because $\beta$ is a power function, the marginal value of children $\beta^{\prime} U$ becomes infinite as fertility tends to zero so $V_{n}(n, y, U) \rightarrow \infty$ as $n \rightarrow 0$. Because the marginal utility of consumption is infinite at zero consumption, $V_{n}(n, y, U) \rightarrow$ $-\infty$ as $n \rightarrow y / \chi$. Continuity of $V_{n}$ then implies that for any finite $y>0$ and finite $U$, there is a unique optimal fertility strictly between zero and $y / \chi$.

Income and children's utility drive fertility. The partial elasticity of fertility with respect to income is

$$
\varepsilon_{n, y} \equiv \frac{y}{n} \frac{\partial n}{\partial y}=-\frac{y V_{n y}}{n V_{n n}}=\left[\frac{b}{\theta} \cdot \frac{c}{y}+\frac{\chi n}{y}\right]^{-1},
$$

which is positive by assumptions on primitives. 

of $\beta^{\prime}$ :

The response of fertility to a change in children's utility depends on the sign

$$
\frac{\partial n}{\partial U}=\frac{\beta^{\prime}}{-V_{n n}} .
$$

Thus in the Barro-Becker case with $\beta^{\prime}>0$, a rise in a children's utility increases fertility, and in the Jones-Schoonbroodt case with $\beta^{\prime}<0$, a rise in children's utility reduces fertility.

\section{The Natural Population Before a Cap is Imposed}

Before a cap is imposed, a perfect-foresight solution is a steady state with constant fertility and utility that solves the household's first-order condition. To see this, note that in any steady state, (4) implies

$$
U=\frac{u(f(e)-\chi n)}{1-\beta(n)}
$$

The steady-state relationship between emissions and fertility is found by substituting (11) into the first-order condition (9) to eliminate $U$ :

$$
S(n, e) \equiv-u^{\prime}(f(e)-\chi n) \chi+\frac{\beta^{\prime}(n)}{1-\beta(n)} u(f(e)-\chi n)=0 .
$$

Before a cap is imposed, the emissions ratio is $e^{+}$. Steady-state fertility $n^{+}$is then the value that solves $S\left(n^{+}, e^{+}\right)=0$. Such an $n^{+}$exists and is unique. ${ }^{8}$ Steady state utility $U^{+}$is the value of $(11)$ at $\left(n^{+}, e^{+}\right)$.

In general, $n^{+}$may be greater or less than one. It is greater than one as long as child costs are not too great a fraction of output. To focus on equilibria in which population grows so any cap would eventually bind, we assume

$$
\chi<\phi f\left(e^{+}\right),
$$

where $\phi \equiv 1 /\left(1+\frac{(1-\theta)\left(1-b_{0}\right)}{(1-b) b_{0}}\right)<1$. Equation (13) rearranges to $S\left(1, e^{+}\right)>0$, which ensures $n^{+}>1$. Then as long as there is no cap, the natural population grows without bound at constant rate $n^{+}-1>0$.

\footnotetext{
${ }^{8}$ As $n \rightarrow f\left(e^{+}\right) / \chi, u^{\prime} \rightarrow \infty$, so $S\left(n, e^{+}\right) \rightarrow-\infty$. In the Barro-Becker case as $n \rightarrow 0, \beta^{\prime} \rightarrow$ $\infty$, so $S\left(n, e^{+}\right) \rightarrow \infty$. Because $S$ is continuous, $S\left(n^{+}, e^{+}\right)=0$ for some $n^{+} \in\left(0, f\left(e^{+}\right) / \chi\right)$. In the Jones-Schoonbroodt case, $1 /(1-\beta(n)) \rightarrow \infty$ as $n \rightarrow n^{\circ}$ from above (where $\beta\left(n^{\circ}\right)=1$ ), so $S\left(n, e^{+}\right) \rightarrow \infty$. Because $S$ is continuous, $S\left(n^{+}, e^{+}\right)=0$ for some $n^{+} \in\left(n^{\circ}, f\left(e^{+}\right) / \chi\right)$. (For $n<n^{\circ}, \beta(n)>1$, so $S<0$.) From (12), $\frac{\partial S}{\partial n}=u^{\prime \prime} \chi^{2}-\frac{\beta^{\prime} u^{\prime} \chi}{1-\beta}+\frac{\beta^{\prime \prime}(1-\beta)-\left(\beta^{\prime}\right)^{2}}{1-\beta} u$, which reduces to $u^{\prime \prime} \chi^{2}+\beta^{\prime \prime} u$ at $n$ such that $S=0$. Because $\beta^{\prime \prime}<0$ and $u>0$ in the Barro-Becker case, and $\beta^{\prime \prime}>0$ and $u<0$ in the Jones-Schoonbroodt case, $\frac{\partial S}{\partial n}<0$. Hence $S$ crosses zero only once.
} 


\section{Natural Population Under a Cap}

After a cap is imposed, population cannot grow without bound because this would eventually drive output $f(e)$ below $\chi$ so fertility would fall below replacement. Thus a cap bounds the natural population. Under a regularity condition described below, the natural population converges monotonically to a unique steady-state level, denoted $N_{s s}$, after a cap is imposed. (Throughout, subscripts $s s$ denotes a variable's steady-state value.) The mechanism is that when $n^{+}>1$, population growth under a cap causes $e_{t}$ to fall over time, which impoverishes households and chokes off fertility.

A perfect-foresight path under a cap must satisfy the recursive definition of utility (4) and the household's first-order condition (9) for all $t$. Equations (4) and (9) can be written as pair of first-order difference equations in $\left\{U_{t}, N_{t}\right\}_{t \geq 0}$ :

$$
\left.U_{t}=u\left(f\left(e\left(N_{t}\right)\right)-\chi \frac{N_{t+1}}{N_{t}}\right)+\beta\left(\frac{N_{t+1}}{N_{t}}\right)\right) U_{t+1},
$$

and

$$
V_{n}(t) \equiv \beta^{\prime}\left(\frac{N_{t+1}}{N_{t}}\right) U_{t+1}-u^{\prime}\left(f\left(e\left(N_{t}\right)\right)-\frac{N_{t+1}}{N_{t}} \chi\right) \chi=0 .
$$

These difference equations and their solution depend on $\hat{E}$ through $e$. We suppress this dependence notationally except when considering how alternative values of $\hat{E}$ affect the economy.

A steady state is a pair $\left(U_{s s}, N_{s s}\right)$ that satisfies (14) and (15) with $U_{t}=$ $U_{t+1}=U_{s s}$ and $N_{t}=N_{t+1}=N_{s s}$. The latter implies steady-state fertility is $n_{s s}=1$. From (14), $U_{s s}$ satisfies (11) with $n=1$ and $e=e_{s s}=e\left(N_{s s}\right)$ Compactly, the steady-state condition under a cap is $S\left(1, e_{s s}\right)=0$. We show in the appendix that $S(1, e)$ crosses zero exactly once on $\left[f^{-1}(\chi), e^{+}\right]$so $e_{s s}$ exists and is unique. Because $S\left(1, e^{+}\right)>0$, it must be that $e_{s s}<e^{+}$so the cap binds in steady state. Accordingly, $N_{s s}=\hat{E} / e_{s s}$ is also unique and $N_{s s}>\hat{E} / e^{+}$.

Because an increase in population lowers household income and hence fertility, one might think that the natural population would necessarily tail off after a cap is imposed and converge monotonically to the steady-state value $N_{s s}$. A complication is that if fertility is too sensitive to changes in population, a population increase from $t$ to $t+1$ can reduce fertility so much that population decreases from $t+1$ to $t+2$. If such "overshooting" were to occur, population would either converge non-monotonically or fail to converge. To rule out complications from overshooting, we restrict the sensitivity of fertility to changes in population by assuming

$$
\varepsilon_{n_{t}, y_{t}}\left(\frac{f^{\prime}\left(e_{t}\right) e_{t}}{f\left(e_{t}\right)}\right)<1
$$


at the steady state and at all $t$, where $\varepsilon_{n_{t}, y_{t}}$ is the partial elasticity of fertility with respect to income (10) and the factor share $f^{\prime}\left(e_{t}\right) e_{t} / f\left(e_{t}\right)$ is also the elasticity of income with respect to population. ${ }^{9}$ We show in the appendix that: $(i)$ condition (16) at the steady state is necessary and sufficient for the system (14) and (15) to have two strictly positive real roots that straddle one, which implies the system is saddle-path stable; and (ii) condition (16) for all $t$ along the saddle path implies that population converges to $N_{s s}$ from any initial population $N_{0}$ and that convergence is monotone from $N_{0} \leq N_{s s} \cdot{ }^{10}$

Fertility along the perfect-foresight natural path (equilibrium natural fertility, $\eta)$ is a function of population and the level of the cap, $n_{t}=\eta\left(N_{t} \mid \hat{E}\right)$. Because $\hat{E}$ enters the model only through (3) as a determinant of $e_{t}$, equilibrium fertility is homogeneous of degree zero: $\eta\left(N_{t} \mid \hat{E}\right)=\eta\left(\xi N_{t} \mid \xi \hat{E}\right)$ where $\xi>0$ is a constant. In words: fertility at population $N_{t}$ under cap $\hat{E}$ equals fertility at population $\xi N_{t}$ under a cap $\xi \hat{E}$, because both have the same $e_{t}$.

Figure 1a illustrates equilibrium natural fertility in the Barro-Becker case. Equilibrium fertility in figure 1a lies below $n^{+}$and falls with $N_{t}$ to the steady state at $N_{s s}$. To understand this, note that a cap has no effect on income as long as $N_{t} \leq \hat{E} / e^{+}$so the cap does not bind, but reduces income once the cap binds. Reduced income in turn reduces fertility increasingly as $N_{t}$ rises above $\hat{E} / e^{+}$. Because the cap eventually binds and utility is determined recursively, utility is less than $U^{+}$as soon as a cap is imposed, which also acts to reduce fertility for all $N_{t}$ in the Barro-Becker case.

Figure 1b illustrates equilibrium natural fertility in the Jones-Schoonbroodt case. Equilibrium fertility lies above $n^{+}$and rises as long as the cap does not bind, then peaks and falls below $n^{+}$as $N_{t}$ becomes closer to $N_{s s}$. This reflects opposing income and utility effects. As in the Barro-Becker case, income declines as $N_{t}$ rises above $\hat{E} / e^{+}$, and utility is less than $U^{+}$. In the Jones-Schoonbroodt case, however, reduced utility raises fertility. This lifts fertility above $n^{+}$when a cap is imposed and causes fertility to rise with $N_{t}$ for $N_{t} \leq \hat{E} / e^{+}$and also for $N_{t}$ slightly above $\hat{E} / e^{+}$. For $N_{t}$ sufficiently close to $N_{s s}$, the income effect dominates and fertility lies below $n^{+}$. Because fertility first rises in the JonesSchoonbroodt case, steady-state population tends to be greater in it than in the Barro-Becker case.

\footnotetext{
${ }^{9}$ Condition (16) is not very strong. Because $\frac{f^{\prime}(e) e}{f(e)}<1$, the condition holds if $\varepsilon_{n, y} \leq 1$. On the other hand, if $\varepsilon_{n, y}>1$ then fertility tends to fall off sharply as a declining emissions ratio reduces income, so the factor share may remain small and (16) can still easily hold. Condition (16) can be ensured by assumptions on primitives. For instance, $b \geq \theta$ implies $\varepsilon_{n, y} \leq 1$ so (16) holds.

${ }^{10}$ One can show that (16) is sufficient for monotone convergence in the Barro-Becker case for all $N_{0}$. For the Jones-Schoonbroodt case, the condition $N_{0} \leq N_{s s}$ is violated only in the (empirically implausible) circumstance in which $\hat{E}<e_{s s} N_{0}$ so the cap immediately forces $e_{0}$ below $e_{s s}$, which means $e_{t}$ rises after the transition period to get to $e_{s s}$. For $N_{0}>N_{s s}$ in the Jones-Schoonbroodt case, technical difficulties concerning monotonicity may arise- see appendix.
} 
Figure 1-- Equilibrium Fertility Functions
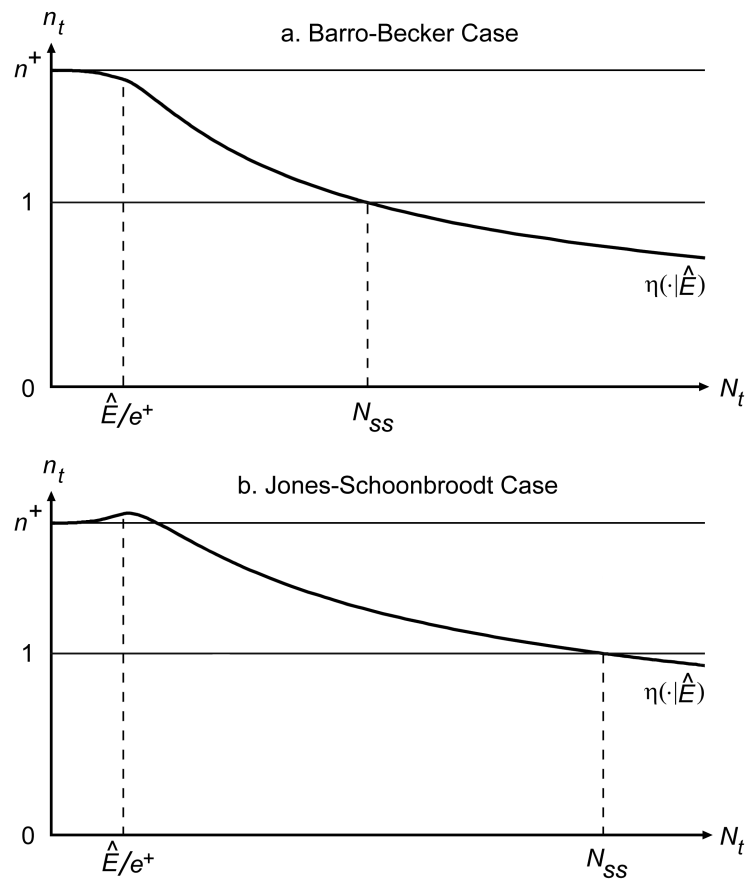

Population dynamics after a cap is imposed can be traced from the equilibrium fertility function. Figure 2 illustrates dynamics in the Barro-Becker case.

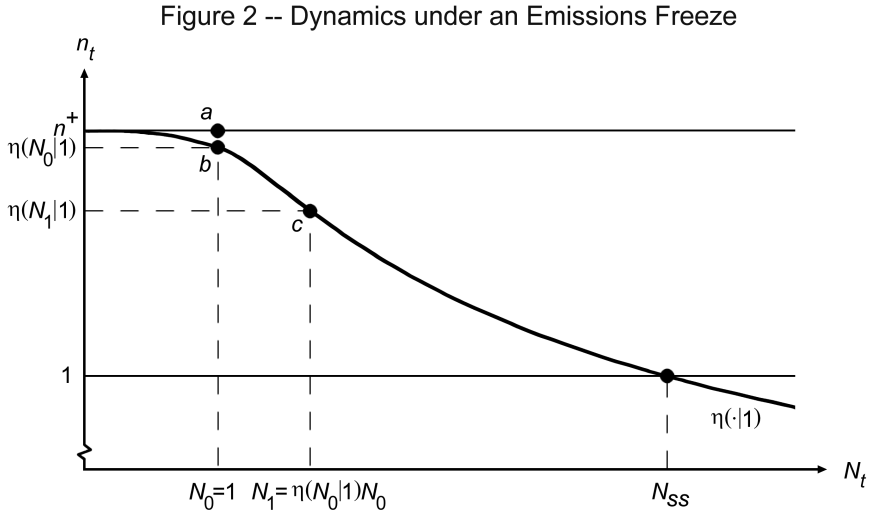

To minimize graphical clutter in figures 2 and 3 , we choose units so $e^{+}=1$ and normalize the population at $t=0$ so $N_{0}=1$. First consider an emissions freeze, meaning a cap set at the emissions level $\hat{E}=e^{+} N_{0}=1$ that would otherwise occur in the uncapped economy at $t=0$. Without a cap, fertility would be $n^{+}$ in period 0 , at point $a$ in the figure. When the cap is imposed, fertility instead jumps down to $\eta\left(N_{0} \mid 1\right)=\eta(1 \mid 1)$, at $b$ on the fertility function. In period 1 , 
the economy is therefore at $c$ with population $N_{1}=\eta\left(N_{0} \mid 1\right) N_{0}=\eta\left(N_{0} \mid 1\right)$ and fertility $\eta\left(N_{1} \mid 1\right)$. The economy then iterates down the fertility function and converges to population $N_{s s}$ with fertility $\eta\left(N_{s s} \mid 1\right)=1$.

Equilibrium fertility functions for caps other than a freeze can be derived from the fertility function for a freeze. For example, consider $\hat{E}=0.75$, a 25 percent cut from the uncapped emissions level $e^{+} N_{0}=1$ in period 0. Because $\eta$ is homogeneous of degree zero, $n_{t}=\eta\left(N_{t} \mid 0.75\right)=\eta\left(N_{t} / 0.75 \mid 1\right)$, so fertility at population $N_{t}$ and cap $\hat{E}=0.75$ equals fertility at population $N_{t} / 0.75$ and $\hat{E}=1$. Graphically, this means the fertility function for a 25-percent emissions cut, $\eta(\cdot \mid 0.75)$, is the fertility function for a freeze, $\eta(\cdot \mid 1)$, shifted 25 percent of the distance to the vertical axis - see figure 3. (Because $N_{s s}=\hat{E} / e_{s s}$ is proportional to $\hat{E}$, steady-state fertility given a 25 -percent cut is also 0.75 times steady-state fertility under a freeze, as in the figure.) By similar reasoning, fertility functions for caps that do not immediately bind (cases with $\hat{E}>e^{+} N_{0}$ ) lie to the right of $\eta(\cdot \mid 1)$.

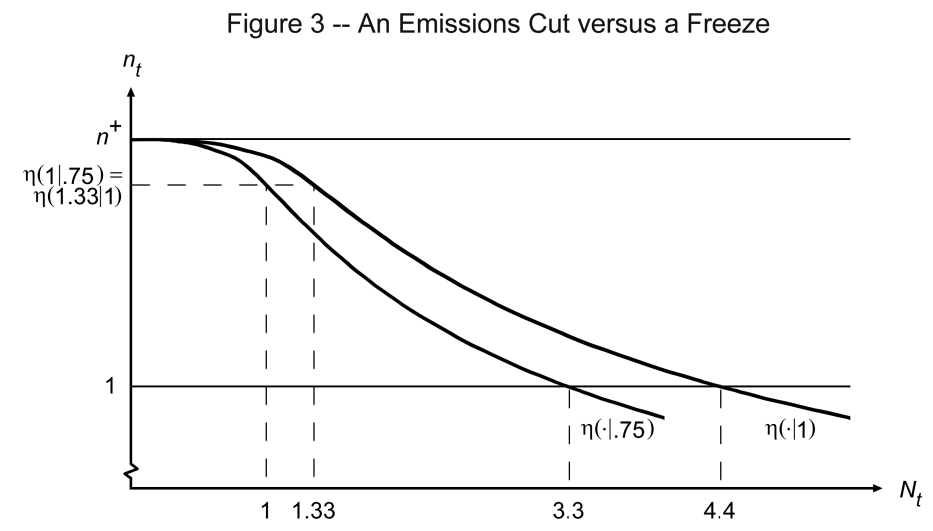

Any cap eventually binds and leads to the same steady-state emission ratio $e_{s s}$. The impact effect of imposing a binding cap is to reduce $e_{0}$ from $e^{+}$to $\hat{E} / N_{0}$; subsequent dynamics take $e_{t}$ the rest of the way to $e_{s s}$. The greater the value of $\hat{E}$ and hence the lower the impact reduction in $e_{0}$, the greater is the adjustment of $e_{t}$ after period 0 .

\section{Optimal Population}

A household is small compared with total population so in maximizing utility, it ignores the reduction in the emissions ratio and hence in everyone's future income caused by having a child. A social planner maximizing the utility of the representative household would take account of this externality. ${ }^{11}$ We first char-

\footnotetext{
${ }^{11}$ Stern (2007) stresses the importance of ethical judgements made in discounting the utilities of future generations. The social planner discounts future generations' utilities at the representative dynasty's own internal discount rate.
} 
acterize the planner's choice of an optimal population sequence and show that this sequence converges monotonically to a steady-state level $N_{s s}^{*}$ that is unique under a regularity condition on $f$ and is less than the natural steady-state population. (Stars denote optimal values throughout.) Thereafter we compare the natural and optimal population sequences to characterize the externality.

The planner at $t=0$ takes $N_{0}$ as given and chooses population levels $N_{1}, N_{2}, \ldots$ to maximize (4), which expands to

$$
U_{0}=u\left(c_{0}\right)+\sum_{t=1}^{\infty}\left[\prod_{j=0}^{t-1} \beta\left(n_{j}\right)\right] u\left(c_{t}\right),
$$

where $n_{t}=N_{t+1} / N_{t}$ and $c_{t}=f\left(e\left(N_{t}\right)\right)-\chi n_{t}$ are functions of $N_{t} \cdot{ }^{12}$

The first-order conditions for the optimal population sequence are

$$
\frac{d U_{0}}{d N_{t+1}}=\left[\prod_{j=0}^{t-1} \beta\left(n_{j}\right)\right] \frac{1}{N_{t}} V_{N_{t+1}}^{*}\left(N_{t}, N_{t+1}, N_{t+2}\right)=0,
$$

for all $t \geq 0$, where

$$
\begin{aligned}
V_{N_{t+1}}^{*}\left(N_{t}, N_{t+1}, N_{t+2}\right) \equiv-u^{\prime}\left(c_{t}\right) \chi & +\beta^{\prime}\left(n_{t}\right) u\left(c_{t+1}\right)+\beta\left(n_{t}\right) \frac{n_{t+1}}{n_{t}} u^{\prime}\left(c_{t+1}\right) \chi \\
& -\frac{\beta\left(n_{t}\right)}{n_{t}} u^{\prime}\left(c_{t+1}\right) f^{\prime}\left(e\left(N_{t+1}\right)\right) e\left(N_{t+1}\right) .
\end{aligned}
$$

More compactly, the first-order conditions consist of the difference equations

$$
V_{N_{t+1}}^{*}\left(N_{t}, N_{t+1}, N_{t+2}\right)=0
$$

for $t \geq 0 .{ }^{13}$

An optimal steady state satisfies $V_{N_{t+1}}^{*}\left(N_{s s}^{*}, N_{s s}^{*}, N_{s s}^{*}\right)=0$ and implies a constant emissions ratio $e_{s s}^{*} \equiv \hat{E} / N_{s s}^{*}$. Define

$$
S^{*}(n, e) \equiv-u^{\prime}(c) \chi+\beta^{\prime}(n) u(c)+\beta(n) u^{\prime}(c)\left[\frac{-f^{\prime}(e) e}{n}+\chi\right],
$$

where $c \equiv f(e)-\chi n$. The right-hand side of (19) reduces to $S^{*}\left(1, \hat{E} / N_{s s}^{*}\right)$ when population is constant at $N_{s s}^{*}$, so $S^{*}\left(1, e_{s s}^{*}\right)=0$ is the condition for an optimal steady state. A root $e_{s s}^{*}$ exists and lies strictly between $e_{s s}$ and $e^{+}$, because $S^{*}=(1-\beta) S-\beta u^{\prime} f^{\prime} e / n$ is continuous in $e$ with $S^{*}\left(1, e_{s s}\right)=-\beta u^{\prime} f^{\prime} e<0$ and

\footnotetext{
${ }^{12}$ In the household problem above, we took fertilities $n_{t}, n_{t+1}, \ldots$ to be the controls. We use population levels $N_{t}, N_{t+1}, \ldots$ as controls in the planner's problem to focus on the externality from an additional person.

${ }^{13}$ We assume the second-order conditions hold. Note that $V_{N_{t+1}}^{*}$ is time-independent so solutions to the planner's problem starting at arbitrary $t>0$ have the same first-order conditions (20) as the problem at $t=0$. This implies that the optimal population sequence is time-consistent.
} 
$S^{*}\left(1, e^{+}\right)=(1-\beta) S\left(1, e^{+}\right)>0$. Because $e_{s s}<e_{s s}^{*}$, the steady-state optimal population $N_{s s}^{*}=\hat{E} / e_{s s}^{*}$ is less than the steady-state natural population $N_{s s}$.

In what follows, we assume $N_{s s}^{*}$ is unique and also assume (16) holds at $N_{s s}^{*}$. Under these conditions, we show in the appendix that the optimal population converges to $N_{s s}^{*}$ from any given initial population $N_{0}$. A sufficient condition for

uniqueness is $\frac{\partial}{\partial e}\left[\frac{f^{\prime} e}{f}\right] \leq 0$, which says the emissions share rises monotonically as a cap increasingly restricts emissions. Then $S^{*}(1, e)$ increases strictly at points where $S^{*}(1, e)=0$ so $S^{*}$ can cross zero only once; details are in the appendix.

As in the case of the natural population above, fertility along the perfectforesight optimal path is a function of population and the level of the cap, $n_{t}=\eta^{*}\left(N_{t} \mid \hat{E}\right)$, where $\eta^{*}$ is homogeneous of degree zero. When a cap is imposed at $t=0$, optimal fertility jumps from $n^{+}$to $\eta^{*}\left(N_{t} \mid \hat{E}\right)$. The jump is always downward in the Barro-Becker case but may be upward or downward in the Jones-Schoonbroodt case. Optimal fertility approaches $n_{s s}^{*}=1$ as population converges to $N_{s s}^{*}$.

\section{A. The Population Externality}

To compare the optimal and natural population paths, note that the firstorder conditions for the optimal population are not satisfied along the natural path. From (19) and the definition of $V_{n}(t)$ in $(15),{ }^{14}$

$$
\begin{aligned}
V_{N_{t+1}}^{*}\left(N_{t}, N_{t+1}, N_{t+2}\right)= & V_{n}(t)-\beta\left(n_{t}\right) \frac{n_{t+1}}{n_{t}} V_{n}(t+1) \\
& -\frac{\beta\left(n_{t}\right)}{n_{t}} u^{\prime}\left(c_{t+1}\right) f^{\prime}\left(e\left(N_{t+1}\right)\right) e\left(N_{t+1}\right),
\end{aligned}
$$

so the first-order conditions that characterize the natural path $\left(V_{n}(t)=0\right.$ for all $t$ ) imply that $V_{N_{t+1}}^{*}$ equals the population externality along the natural path:

$$
V_{N_{t+1}}^{*}\left(N_{t}, N_{t+1}, N_{t+2}\right)=-\frac{\beta\left(n_{t}\right)}{n_{t}} u^{\prime}\left(c_{t+1}\right) f^{\prime}\left(e\left(N_{t+1}\right)\right) e\left(N_{t+1}\right)<0 .
$$

From (18), $V_{N_{1}}^{*}=N_{0} \frac{d U_{0}^{*}}{d N_{1}}$ is the period-0 population times the change in a parent's utility at $t=0$ caused by a marginal child. More generally, the analogue

$$
\begin{aligned}
& { }^{14} \text { From (15), } \\
& \begin{aligned}
V_{n}(t)-\beta\left(n_{t}\right) \frac{n_{t+1}}{n_{t}} V_{n}(t+1) \\
=\left[-u^{\prime}\left(c_{t}\right) \chi+\beta^{\prime}\left(n_{t}\right) U_{t+1}\right]-\beta\left(n_{t}\right) \frac{n_{t+1}}{n_{t}}\left[-u^{\prime}\left(c_{t+1}\right) \chi+\beta^{\prime}\left(n_{t+1}\right) U_{t+2}\right] \\
=-u^{\prime}\left(c_{t}\right) \chi+\beta^{\prime}\left(n_{t}\right)\left[U_{t+1}-\beta\left(n_{t}\right) \frac{n_{t+1}}{n_{t}} \frac{\beta^{\prime}\left(n_{t+1}\right)}{\beta^{\prime}\left(n_{t}\right)} U_{t+2}\right]+\beta\left(n_{t}\right) \frac{n_{t+1}}{n_{t}} u^{\prime}\left(c_{t+1}\right) \chi \\
=-u^{\prime}\left(c_{t}\right) \chi+\beta^{\prime}\left(n_{t}\right) u\left(c_{t+1}\right)+\beta\left(n_{t}\right) \frac{n_{t+1}}{n_{t}} u^{\prime}\left(c_{t+1}\right) \chi,
\end{aligned}
\end{aligned}
$$

where the final step uses (4) and the power form of $\beta$, which implies $n \beta^{\prime}(n)=(1-b) \beta(n)$ so $\beta\left(n_{t}\right) \frac{n_{t+1}}{n_{t}} \frac{\beta^{\prime}\left(n_{t+1}\right)}{\beta^{\prime}\left(n_{t}\right)}=\beta\left(n_{t+1}\right)$. 
of (17) for the planner at an arbitrary period $t$, denoted $U_{t}^{*}$, can be differentiated to yield $V_{N_{t+1}}^{*}=N_{t} \frac{d U_{t}^{*}}{d N_{t+1}}$, so the aggregate population externality measured by (22) is the period- $t$ adult population times the change in an adult's utility for any $t \geq 0$.

The term $-f^{\prime}\left(e_{t+1}\right) e_{t+1}$ in $(22)$ is the aggregate real externality measured in units of output at $t+1$ and $\beta\left(n_{t}\right) u^{\prime}\left(c_{t+1}\right) / n_{t}$ converts this into units of parents' (period- $t$ ) utility. There are two interpretations of the real part. The first is the loss of output caused by a marginal birth: the derivative of $f\left(e\left(N_{t+1}\right)\right)$ with respect to population is $-f^{\prime}\left(e_{t+1}\right) e_{t+1} / N_{t+1}$; summing over the population $N_{t+1}$ gives an aggregate loss of $-f^{\prime}\left(e_{t+1}\right) e_{t+1}$. The second is the dilution of rents from auction revenue caused by a marginal birth. When government auctions $E$ permits, it receives total revenue $p_{t} E=f^{\prime} E$ that it redistributes as equal lump sums so each person indirectly receives emission revenue $f^{\prime} e$. With an additional birth at $t$, the population at $t+1$ loses the revenue $f^{\prime}\left(e_{t+1}\right) e_{t+1}$ that goes to the additional person.

Each adult at $t+1$ loses consumption of $f^{\prime}\left(e_{t+1}\right) e_{t+1} / N_{t+1}$, which is a utility loss of $u^{\prime}\left(c_{t+1}\right) f^{\prime}\left(e_{t+1}\right) e_{t+1} / N_{t+1}$ for each child of a parent at $t$. From (4), a parent's utility is the weight $\beta\left(n_{t}\right)$ times the utility of a child so multiplying the child's per-capita utility loss by $\beta\left(n_{t}\right)$ and summing over the $N_{t}$ individuals alive in period $t$ gives an aggregate externality in terms of parents' utility of $-N_{t} \beta\left(n_{t}\right) u^{\prime}\left(c_{t+1}\right) f^{\prime}\left(e_{t+1}\right) e_{t+1} / N_{t+1}$, which is the right-hand side of (22).

From (22), the population externality equals zero in the uncapped economy because $f^{\prime}\left(e^{+}\right)=0$. Thus in the uncapped economy, the natural and optimal populations are equal, so we can conclude it is the imposition of the cap that induces the population externality and causes the optimal and natural populations to differ. Also from (22), the optimal population at $t+1$ in the capped economy is less than the natural population at $t+1$ for any $t$.

Condition (22) captures the population externality from marginal birth at $t$ with all population levels after $t+1$ given. A birth at $t$, however, creates a new dynasty whose members increase populations after $t+1$ and also generate externalities. To derive an expression for the overall externality from a marginal birth, let $V^{*}(N)$ denote the maximized value of the planner's problem written generically as a function of the population the planner inherits, $N$. Because the problem is time-invariant, $V^{*}$ satisfies the Bellman equation

$$
V^{*}(N)=\max _{n}\left\{u(f(e(N))-\chi n)+\beta(n) V^{*}(n N)\right\},
$$

for all feasible $N$, and optimal fertility $n^{*}=\eta^{*}(N \mid \hat{E})$ satisfies the first-order condition

$$
\begin{aligned}
V_{n}^{*} & \equiv-u^{\prime}(f(e(N))-\chi n) \chi+\beta^{\prime}(n) V^{*}(n N)+\beta(n) N \frac{d V^{*}}{d N}(n N) \\
& =V_{n}\left(n, f(e(N)), V^{*}(n N)\right)+\beta(n) N \frac{d V^{*}}{d N}(n N)=0 .
\end{aligned}
$$

As in the derivation of (22), the household sets $V_{n}=0$ so $\beta(n) N \frac{d V^{*}}{d N}(n N)$ captures externalities. Because the value function by construction assumes optimal 
fertility for the entire future, the externality term in this case captures all future externalities.

To re-express $\beta(n) N \frac{d V^{*}}{d N}(n N)$ explicitly as a sum of future single-period externalities, the envelope theorem applied to $(23)$ breaks $\frac{d V^{*}}{d N}(n N)$ into current and future terms:

$$
\begin{aligned}
\frac{d V^{*}}{d N}\left(n_{t}^{*} N_{t}^{*}\right)= & \frac{d V^{*}}{d N}\left(N_{t+1}^{*}\right) \\
= & -u^{\prime}\left(f\left(e\left(N_{t+1}^{*}\right)\right)-\chi n_{t+1}^{*}\right) f^{\prime}\left(e\left(N_{t+1}^{*}\right)\right) \frac{e\left(N_{t+1}^{*}\right)}{N_{t+1}^{*}} \\
& +\beta\left(n_{t+1}^{*}\right) n_{t+1}^{*} \frac{d V^{*}}{d N}\left(N_{t+2}^{*}\right) .
\end{aligned}
$$

By reapplying (25) iteratively to eliminate successive future derivatives of $V^{*}$, we obtain

$$
\frac{d V^{*}}{d N}\left(N_{t+1}^{*}\right)=-\frac{1}{N_{t+1}^{*}} \sum_{i=1}^{\infty}\left[\prod_{j=1}^{i-1} \beta\left(n_{t+j}^{*}\right)\right] u^{\prime}\left(c_{t+i}^{*}\right) f^{\prime}\left(e\left(N_{t+i}^{*}\right)\right) e\left(N_{t+i}^{*}\right),
$$

where $c_{t+i}^{*}=f\left(e\left(N_{t+i}^{*}\right)\right)-\chi n_{t+i}^{*}$. In (27), the overall externality from a marginal birth in period $t$ is a discounted sum of all future population externalities caused by the birth, evaluated along the optimal path.

\section{B. Pigovian Taxes on Having Children}

We compute the sequence of child taxes that would be needed to change fertility and population from natural to optimal levels, assuming that resulting revenue is redistributed to households as equal lump sums. Formally, let $\tau_{t}$ denote the tax per child and let $\bar{n}_{t}$ denote the average over households of $n_{t}$ in $t$, so each household pays child taxes $\tau_{t} n_{t}$ and receives lump-sum revenue $\tau_{t} \bar{n}_{t}$. One can think of $\tau_{t}$ as aggregating into single number the combined effect of a range of actual policies that affect the net incentive to have children. ${ }^{15}$

Zero child taxes by definition results in the natural population. With child taxes, overall child costs include taxes and overall transfers includes lump-sum redistributions of child-tax revenue, so the household generically maximizes $u(w+T R-\chi n-\tau n)+\beta(n) U$ taking $w, T R=p E / N+\tau \bar{n}$, and $\tau$ as given. The first-order condition is

$$
V_{n}(n, w+T R, U \mid \tau) \equiv-u^{\prime}(w+T R-\chi n-\tau n)(\chi+\tau)+\beta^{\prime} U=0 .
$$

\footnotetext{
${ }^{15}$ Examples include filing-status differences, personal exemptions, public-school spending levels and regulations that affect public-school quality, and welfare eligibility rules and benefits levels. (In an overlapping-generations model in which parents have children partly to provide for own old age, $\tau_{t}$ might also include the reduced incentive to have children caused by social security.) There is no guarantee that a given population policy can be implemented in practice. Extracting taxes from parents with low income may sometimes be difficult, for instance, and some ways of preventing population growth may be ethically unacceptable.
} 
To implement the optimal population sequence, each optimal tax $\tau_{t}^{*}$ must be set so $n_{t}^{*}$, which solves (24), also solves (28). Setting $V_{n}^{*}$ from (24) equal to $V_{n}$ from (28) and noting that $w_{t}+T R_{t}-\tau_{t}^{*} n_{t}^{*}=f\left(e\left(N_{t}^{*}\right)\right)$ and $U_{t+1}=$ $V^{*}\left(N_{t+1}^{*}\right)$ along the optimal path, $\tau_{t}^{*}$ must satisfy $u^{\prime}\left(f\left(e\left(N_{t}^{*}\right)\right)-\chi n_{t}^{*}\right) \tau_{t}^{*}=$ $-\beta\left(n_{t}^{*}\right) N_{t}^{*} \frac{d V^{*}}{d N}\left(N_{t+1}^{*}\right)$. From $(27)$,

$$
\begin{aligned}
\tau_{t}^{*} & =\frac{\beta\left(n_{t}^{*}\right) N_{t}^{*}}{u^{\prime}\left(c_{t}^{*}\right)}\left(-\frac{d V^{*}}{d N}\left(N_{t+1}^{*}\right)\right) \\
& =\frac{\beta\left(n_{t}^{*}\right)}{n_{t}^{*}} \sum_{i=1}^{\infty}\left[\prod_{j=1}^{i-1} \beta\left(n_{t+j}^{*}\right)\right] \frac{u^{\prime}\left(c_{t+i}^{*}\right)}{u^{\prime}\left(c_{t}^{*}\right)} f^{\prime}\left(e\left(N_{t+i}^{*}\right)\right) e\left(N_{t+i}^{*}\right) .
\end{aligned}
$$

Two things follow. First, whether or not the cap imposed at $t=0$ binds immediately, optimal taxes are positive for all $t \geq 0$. This is because population will grow to exceed $\hat{E} / e^{+}$after a finite number of periods, at which time $f^{\prime}\left(e\left(N_{t+i}^{*}\right)\right) e\left(N_{t+i}^{*}\right)>0$ so the discounted value in (29) is strictly positive for all $t \geq 0$. Second, optimal child taxes are Pigovian, as in Harford (1998): the optimal tax at arbitrary period $t$ equals the discounted present value of the externalities generated by a child and all descendants of the child. The terms $f^{\prime}\left(e\left(N_{t+1}^{*}\right)\right) e\left(N_{t+1}^{*}\right)$ are the real externalities and the other terms can be written as the number of descendants in a future period times products of single-period discount factors. ${ }^{16}$

\section{Permanent Property Rights}

The population externality can be thought of as resulting from imperfect property rights. This section shows there is no population externality if government issues permanent emissions rights instead of permits valid for only a single period. With single-period permits, a marginal birth means more individuals share a given total amount of emissions rights in the next period so next-period per-person emission rights are diluted. With permanent rights, on the other hand, total rights to emit in the next period are given and hence not diluted. Instead, when a household has an additional child, it is the emission rights of the household's own children that are diluted. This provides a disincentive to have children equal to that induced by optimal Pigovian taxes.

\footnotetext{
${ }^{16}$ In detail,

$$
\frac{\beta\left(n_{t}^{*}\right)}{n_{t}^{*}}\left[\prod_{j=1}^{i-1} \beta\left(n_{t+j}^{*}\right)\right] \frac{u^{\prime}\left(c_{t+i}^{*}\right)}{u^{\prime}\left(c_{t}^{*}\right)}=\left(\prod_{j=1}^{i-1} n_{t+j}^{*}\right)\left[\prod_{j=0}^{i-1} \frac{\beta\left(n_{t+j}^{*}\right)}{n_{t+j}^{*}} \frac{u^{\prime}\left(c_{t+j+1}^{*}\right)}{u^{\prime}\left(c_{t+j}^{*}\right)}\right],
$$

where $\prod_{j=1}^{i-1} n_{t+j}^{*}=L_{t+i}^{*} / L_{t+1}^{*}$ is the number of descendants at time $t+i$ per child born at time $t+1$. The terms $\frac{\beta\left(n_{t+j}^{*}\right)}{n_{t+j}^{*}} \frac{u^{\prime}\left(c_{t+j+1}^{*}\right)}{u^{\prime}\left(c_{t+j}^{*}\right)}$ can be interpreted as single-period discount factors. Specifically, if individuals could trade consumption loans that are settled by their children, $\frac{\beta\left(n_{t+j}^{*}\right)}{n_{t+j}^{*}} \frac{u^{\prime}\left(c_{t+j+1}^{*}\right)}{u^{\prime}\left(c_{t+j}^{*}\right)}$ would be the market-clearing price in period $j$ of a loan that pays one consumption unit in period $j+1$.
} 
To formalize this, suppose the government at $t=0$ simply gives the household rights to emit $\pi_{0}=\hat{E} / N_{0}$ units of greenhouse gases each period in perpetuity. A household in period $t$ with permanent rights to emit $\pi_{t}$ units rents these to the firm at the competitive price $p_{t}=f^{\prime}$ in the period, then leaves an equal share to each child so emission rights evolve as $\pi_{t+1}=\pi_{t} / n_{t}$. The latter captures the dilution of each child's inheritance from a marginal child and implies $\pi_{t}=e\left(N_{t}\right)$ for all $t$. The household earns wage $w_{t}=f-e_{t} f^{\prime}$ and consumes $c_{t}=w_{t}+\pi_{t} p_{t}-\chi n_{t}=f\left(e_{t}\right)-\chi n_{t}$. We show in the appendix that the natural population sequence with such permanent, inheritable emissions rights is the optimal sequence.

Permanent property rights exist in the real world for land. Permanent emission rights would be similar except that they would be created on paper by government and be rights to the revenue from one unit of emissions per-period, forever. Permanent emission rights mean the government at $t=0$ binds all future governments, which may be difficult to achieve in practice. Permanence would fail if future governments were to tax or reallocate emission rights, which may benefit a majority of voters. With heterogeneous agents, for instance, dynasties with a heritable preference to have more children would over time form a relatively impoverished majority that would gain from redistribution. Similarly, permanence might be problematic if governments were to change the cap level in response to new information about the environmental effects of greenhouse gas emissions.

\section{Extensions}

To set the stage for calibrations, we extend the model in three ways:

\section{A. Time costs of children}

To now we have ignored the substantial time parents devote to children. To include such time costs, assume each adult has a unit endowment of time that is devoted either to work or having children, and suppose having a child requires a constant amount of parental time, $\psi$, in addition to output $\chi$. (We continue to abstract from pure leisure.) Time spent having a child reduces labor supply so $l_{t}=1-\psi n_{t}$ becomes variable, total labor supply $L_{t}=\left(1-\psi n_{t}\right) N_{t}$ must be distinguished from population $N_{t}$, and the emissions ratio depends on fertility:

$$
e_{t}=\min \left(e^{+}, \frac{\hat{E}}{\left(1-\psi n_{t}\right) N_{t}}\right) \text {. }
$$

An increase in $n_{t}$ has an additional (productivity-increasing) effect: greater fertility reduces labor, driving up $e_{t}$.

With time costs, the cost of a child depends on the wage $w(e)$ and becomes $\chi+\psi w\left(e_{t}\right)$, the sum of the output cost and foregone wages. ${ }^{17}$ Because the

\footnotetext{
${ }^{17}$ The marginal cost of a child to the planner is also $\chi+\psi w(e)$. From the planner's
} 
household takes the wage and transfers of permit revenue $T R_{t}=p_{t} E_{t} / N_{t}$ as given in maximizing utility, these replace income as exogenous determinants of fertility. In equilibrium, household income is the sum of wage income and transfers, and equals labor times output per unit of labor:

$$
y_{t}=\left(1-\psi n_{t}\right) w\left(e_{t}\right)+f^{\prime}\left(e_{t}\right) E_{t} / N_{t}=\left(1-\psi n_{t}\right) f\left(e_{t}\right),
$$

which replaces (8). The generic household first-order condition becomes

$$
V_{n}(n, w, T R, U) \equiv-u^{\prime}((1-\psi n) w+T R-\chi n) \cdot(\chi+\psi w)+\beta^{\prime} U=0 .
$$

These changes carry through the resulting dynamics in a straightforward way and are easily incorporated into calibrations. Notably, the function $S$ defined in (12) gains terms and becomes

$$
\begin{aligned}
S(n, e) \equiv-u^{\prime}((1-\psi n) f(e)-\chi n)( & +\psi w(e)) \\
& +\frac{\beta^{\prime}(n)}{1-\beta(n)} u((1-\psi n) f(e)-\chi n) .
\end{aligned}
$$

Roots of the resulting steady-state conditions $S\left(n^{+}, e^{+}\right)=0$ and $S\left(1, e_{s s}\right)=0$ exist. These roots are steady-state values of fertility before a cap is imposed, $n^{+}$, and of the emissions ratio after a cap is imposed, $e_{s s}$. Condition (13), which ensures $n^{+}>1$, gains a time-cost term $\psi f\left(e^{+}\right)$and becomes $\chi+\psi f\left(e^{+}\right)<$ $\phi f\left(e^{+}\right)$. The steady-state natural population is

$$
N_{s s}=\frac{\hat{E}}{(1-\psi) e_{s s}}
$$

The planner's problem with time costs similarly implies a steady-state optimal emissions share $e_{s s}^{*}$ with $e_{s s}<e_{s s}^{*}<e^{+}$, and steady-state optimal population $N_{s s}^{*}=\hat{E} /\left[(1-\psi) e_{s s}^{*}\right]<N_{s s} .{ }^{18}$

With time costs, population increases that lower $e_{t}$ and hence $w_{t}$ also reduce the time cost of having children. The reduced cost acts to increase natural and optimal fertilities during the transition to the steady state. We allow for time costs $\psi \geq 0$ in the remainder of the paper.

\section{B. Backstop Technology}

To now we have also assumed it is impossible to produce output without generating emissions. This is restrictive given that a common assumption in

perspective, $c=(1-\psi n) f(e)-\chi n$ implies $\frac{d c}{d n}=-(\chi+\psi f(e))+(1-\psi n) f^{\prime}(e) \frac{d e}{d n}$. For $e=e^{+}, f(e)=w(e)$ and $f^{\prime}(e)=0$ so $\frac{d c}{d n}=-(\chi+\psi w(e))$. For $e<e^{+}, \frac{d e}{d n}=\frac{\psi e}{1-\psi n}$, so $\frac{d c}{d n}=-(\chi+\psi f(e))+\psi f^{\prime}(e) e=-(\chi+\psi w(e))$.

${ }^{18}$ The condition for an optimal steady state is $S^{*}=S-\frac{\beta(n)}{n} u^{\prime}(c)(1-\psi n) f^{\prime}(e) e=0$. A technical caveat is that uniqueness of $e_{s s}$ and $e_{s s}^{*}$ requires regularity conditions. These conditions are detailed in the appendix and are satisfied in the calibrations below. 
integrated assessment models is that a "backstop" technology may permit positive output to be produced without emissions. ${ }^{19}$ Formally, the value of $f(0)$ is the backstop level of output per unit of labor.

Steady-state natural and optimal populations still exist with a positive backstop as long as $f(0)$ is low enough. Specifically, if $f(0)<\chi /(1-\psi)$, then there is an $e=f^{-1}(\chi /(1-\psi))>0$ at which the marginal utility of consumption is infinite so $S\left(1, f^{-1}(\chi /(1-\psi))\right)<0$, with $S$ as defined in (31), and the steady-state analysis in section III holds, mutatis mutandis. Moreover if $f(0) \geq \chi /(1-\psi)$ but

$$
f(0)<f^{B} \equiv \frac{\chi}{\phi-\psi},
$$

then $S(1,0)<0$, and again the reasoning of section III implies there is a unique steady-state natural emissions ratio $e_{s s}>0$ defined by $S\left(1, e_{s s}\right)=0$.

If $f(0)>f^{B}$, on the other hand, the natural population does not converge to a steady-state value. Instead, fertility converges to the unique root $n_{s s}$ of $S\left(n_{s s}, 0\right)=0 .^{20}$ The root satisfies $n_{s s}>1$ so population grows without bound, the emissions ratio converges to zero, $f\left(e_{t}\right)$ converges to $f(0)$, and per-capita output converges to $\left(1-\psi n_{s s}\right) f(0)$. In the limit as $e \rightarrow 0$, concavity implies $f^{\prime}(e) e \rightarrow 0$ so the population externality vanishes, and optimal fertility converges to the same limit $n_{s s}$ as natural fertility. However, the population externality exists for all $t \geq 0$ and the welfare results in section IV apply. ${ }^{21}$ Most importantly, natural fertility exceeds optimal fertility and the optimal child tax is positive. Because these hold for all $t \geq 0$, the natural population exceeds the optimal population even in the limit.

The backstop output level $f(0)$ is key to knowing the economy's fate under a cap. As long as $f(0)<f^{B}$, a cap will ultimately cause the economy to converge to a steady state in which output is low enough to choke off fertility, even if the cost of eliminating almost all emissions is small: fertility in this case would remain high right after a cap is imposed and $e$ would continue to drop until output eventually falls enough to choke off fertility. Unfortunately, it may be hard to know how much the economy would produce at $e=0$ from experience at $e=e^{+}$. Calibrations below explore the role of $f(0)$.

\section{Productivity Growth}

To add productivity growth, we replace the production function (1) with

$$
Y_{t}=F\left(L_{t} \lambda^{t}, E_{t} \alpha^{t}\right)
$$

\footnotetext{
${ }^{19}$ e.g. Nordhaus and Boyer (2000), Kelly and Kolstad (2001).

${ }^{20}$ The limit conditions change when $f(0)>f^{B}$. For the natural population, $S\left(n_{s s}, 0\right)=$ 0 replaces $S\left(1, e_{s s}\right)=0$ (which applies when $f(0)<f^{B}$ ). For the optimal population, $S^{*}\left(n_{s s}^{*}, 0\right)=0$ replaces $S^{*}\left(1, e_{s s}^{*}\right)=0$, where $S^{*}$ is as defined in footnote 18 . In the nongeneric case with $f(0)=f^{B}$, both natural limit conditions reduce to $S(1,0)=0$ and both optimal limit conditions reduce to $S^{*}(1,0)=0$.

${ }^{21}$ Because $e_{t} l_{t} N_{t}=\hat{E}$, a value $e_{t}=0$ is inconsistent with $\hat{E}>0$. For this reason, there is no meaningful $e_{s s}$ equal to zero, but allocations with $e_{t}>0$ in which $e_{t} \rightarrow 0$ are still meaningful.
} 
where $\lambda \geq 1$ is an exogenously given growth factor for labor productivity and $\alpha \geq 1$ is an exogenously given growth factor for emissions productivity. Greater emissions productivity $\alpha^{t}$ means that fewer emissions are generated in producing a given amount of output from a given amount of labor.

We assume the output cost of a child grows with the level of labor productivity $\lambda^{t}$ so we replace the household budget (7) with

$$
c_{t}=y_{t}-\lambda^{t} \chi n_{t} .
$$

Including productivity in this way can be thought of an assumption about human capital: greater productivity means greater human capital, which requires that more resources be put into each child. ${ }^{22}$

A growing economy is equivalent to a non-growing economy with productivityadjusted variables and parameters, marked with tildes. The key state variable is growth-adjusted population, $\tilde{N}_{t} \equiv N_{t} \lambda^{t} / \alpha^{t}$. Also define $\tilde{n}_{t} \equiv n_{t} \lambda / \alpha$; this is the growth factor for productivity-adjusted population and for total emissions, which rise over time because of population growth $\left(n_{t}\right)$ and labor productivity growth $(\lambda)$, and decrease because of growth in emissions productivity $(\alpha)$. In addition, define $\tilde{e}_{t} \equiv \min \left(e^{+}, \frac{\hat{E}}{\left(1-\tilde{\psi} \tilde{n}_{t}\right) \tilde{N}_{t}}\right), \tilde{y}_{t} \equiv\left(1-\tilde{\psi} \tilde{n}_{t}\right) f\left(\tilde{e}_{t}\right)=y_{t} / \lambda^{t}$, $\tilde{w}_{t} \equiv f\left(\tilde{e}_{t}\right)-f^{\prime}\left(\tilde{e}_{t}\right) \tilde{e}_{t}, \tilde{\chi} \equiv \chi \alpha / \lambda$ (so $\left.\tilde{\chi} \tilde{n}_{t}=\chi n_{t}\right), \tilde{\psi} \equiv \psi \alpha / \lambda$ (so $\tilde{\psi} \tilde{n}_{t}=\psi n_{t}$ ), $\tilde{\beta}\left(\tilde{n}_{t}\right) \equiv \lambda^{(1-\theta)} \beta\left(\tilde{n}_{t} \alpha / \lambda\right)=\lambda^{(1-\theta)} \beta\left(n_{t}\right), \tilde{U}_{t} \equiv U_{t} / \lambda^{(1-\theta) t}, \tilde{\tau}_{t} \equiv \tau_{t}(\alpha / \lambda) / \lambda^{t}$, and $\widetilde{T R}_{t}=f^{\prime}\left(\tilde{e}_{t}\right) E_{t} / \tilde{N}_{t}+\tilde{n}_{t} \tilde{\tau}_{t}$.

With these definitions (and $\left.T R_{t}=f^{\prime}\left(e_{t}\right) E_{t} / N_{t}+n_{t} \tau_{t}\right)$ :

$$
\begin{aligned}
u\left(\left(1-\psi n_{t}\right) w_{t}\right. & \left.+T R_{t}-\left(\lambda^{t} \chi+\tau_{t}\right) n_{t}\right)+\beta\left(n_{t}\right) U_{t+1} \\
& =\lambda^{(1-\theta) t}\left[u\left(\left(1-\tilde{\psi} \tilde{n}_{t}\right) \tilde{w}_{t}+\widetilde{T R} R_{t}-\left(\tilde{\chi}+\tilde{\tau}_{t}\right) \tilde{n}_{t}\right)+\tilde{\beta}(\tilde{n}) \tilde{U}_{t+1}\right],
\end{aligned}
$$

so choosing $n$ to maximize $u((1-\psi n) w+T R-(\chi+\tau) n)+\beta(n) U$ with given $(w, T R, U)$ is equivalent to choosing $\tilde{n}$ to maximize $u((1-\tilde{\psi} \tilde{n}) \tilde{w}+\widetilde{T R}-(\tilde{\chi}+$ $\tilde{\tau}) \tilde{n})+\tilde{\beta}(\tilde{n}) \tilde{U}$ with given $(\tilde{w}, \widetilde{T R}, \tilde{U})$. The equivalent problem has the same form as the problem without productivity growth except that growth-adjusted (tilde) variables replace regular variables. Along any equilibrium path, consumption is $\tilde{c}_{t}=\left(1-\tilde{\psi} \tilde{n}_{t}\right) \tilde{w}_{t}+\widetilde{T R}_{t}-\left(\tilde{\chi}+\tilde{\tau}_{t}\right) \tilde{n}_{t}=\left(1-\tilde{\psi} \tilde{n}_{t}\right) f\left(\tilde{e}_{t}\right)-\tilde{\chi} \tilde{n}_{t}$. All analysis from previous sections goes through with growth-adjusted variables replacing regular variables.

Before a cap it imposed, the emissions ratio is $\tilde{e}_{t}=e^{+}$and household income follows $y_{t}^{+} \equiv\left(1-\tilde{\psi} \tilde{n}_{t}\right) f\left(e^{+}\right) \lambda^{t}$. A perfect-foresight solution is pair $\left(\tilde{n}^{+}, \tilde{U}^{+}\right)$with $\tilde{U}^{+}=u\left(\left(1-\tilde{\psi} \tilde{n}^{+}\right) f\left(e^{+}\right)-\tilde{\chi} \tilde{n}^{+}\right) /\left(1-\tilde{\beta}\left(\tilde{n}^{+}\right)\right)$, where $\tilde{n}^{+}$is optimal given $\tilde{U}^{+}$. In any solution, the growth-adjusted population grows at rate $\tilde{n}^{+}-1$ in all periods

\footnotetext{
${ }^{22}$ The term $\lambda^{t}$ corresponds roughly to Becker's (1960) "child quality." The proportionality of the output cost of a child to $\lambda^{t}$ ensures that child costs do not vanish or explode as a fraction of income merely because productivity grows. This implies a balanced-growth path with constant $n_{t}$ in the uncapped economy, which simplifies comparisons with the capped economy.
} 
without a cap. Because $E_{t}=\tilde{e}_{t}\left(1-\tilde{\psi} \tilde{n}^{+}\right) \tilde{N}_{t}$ and $\tilde{e}_{t}=e^{+}$, emissions grow at the same rate $\tilde{n}^{+}-1$ before a cap is imposed. We assume $\tilde{\chi}+\tilde{\psi} f\left(e^{+}\right)<\tilde{\phi} f\left(e^{+}\right)$, where $\tilde{\phi}=1 /\left(1+\frac{(1-\theta)(1-\tilde{\beta}(1))}{(1-b) \tilde{\beta}(1)}\right)<1$, so $\tilde{n}^{+}>1 .^{23}$ This implies that growth of $\tilde{N}_{t}$ eventually would drive $\frac{\hat{E}_{t}}{\left(1-\tilde{\psi} \tilde{n}_{t}\right) \tilde{N}_{t}}$ below $e^{+}$, so any cap would eventually bind.

Growth-adjusted population is bounded under a cap and converges to a steady-state value $\tilde{N}_{s s}$. Thus unless $\alpha=\lambda$, the actual population $N_{t}$ changes over time. Specifically, $\tilde{n}_{s s}=n_{s s} \lambda / \alpha=1$ implies that actual fertility converges to the steady-state value $n_{s s}=\alpha / \lambda$. This is a balanced-growth condition. Namely, the production function (34) implies that output growth arises from growth in the two inputs $l_{t} N_{t} \lambda^{t}$ and $E_{t} \alpha^{t}$. In steady state with actual fertility constant at $n_{s s}$, effective labor $\left(1-\psi n_{s s}\right) N_{t} \lambda^{t}$ has growth factor $n_{s s} \lambda$. Because emissions are capped at $\hat{E}$, the input $E_{t} \alpha^{t}$ has growth factor $\alpha$. Balanced growth requires $n_{s s} \lambda=\alpha$, or $n_{s s}=\alpha / \lambda$. By the same logic, steady-state optimal fertility satisfies $n_{s s}^{*}=\alpha / \lambda$.

A simple intuition for the balanced-growth condition is that growth in labor productivity $(\lambda)$ introduces an increasing trend in each person's emissions footprint, and growth in emissions productivity $(\alpha)$ introduces a decreasing trend in each person's emissions footprint. On net, exogenous productivity growth therefore introduces growth in per-capita emissions with the factor $\lambda / \alpha$ per period. To hold total emissions constant in steady state, this means that population must fall with factor $\lambda / \alpha$, or equivalently, that steady-state population must rise with factor $\alpha / \lambda$.

Thus if productivity growths of emissions and labor are equal $(\alpha=\lambda)$, population is constant in steady state. If labor productivity grows but emissions productivity is constant $(\lambda>1$ and $\alpha=1)$, population shrinks at the rate of labor productivity growth. On the other hand, population grows forever if emissions productivity grows more rapidly than labor productivity $(\alpha>\lambda)$.

It is useful to distinguish three growth rates in the capped economy in steady state. Output per person and hence living standards always grow with factor $\lambda$. With balanced growth under an emissions cap, total output grows with the emissions-productivity factor $\alpha$. Because total output grows with factor $\alpha$ and total output divided by population grows with factor $\lambda$, population grows with factor $\alpha / \lambda$. The outcome is Malthusian modified for productivity growth: living standards and total output continue to grow as long as $\lambda$ and $\alpha$ are positive, and population grows (or shrinks) unless $\alpha=\lambda$.

Note that taxes in the transformed economy, $\tilde{\tau}_{t} \equiv \tau_{t}(\alpha / \lambda) / \lambda^{t}$, are taxes per growth-adjusted child. To express the optimal Pigovian taxes $\tilde{\tau}_{t}^{*}$ as taxes per actual child $\left(\tau_{t}^{*}\right)$, it is necessary to divide out the factor $(\alpha / \lambda) / \lambda^{t}$. The actual tax grows with factor $\lambda$, as does actual income along the optimal path,

\footnotetext{
${ }^{23}$ Emissions have increased historically, consistent with $\tilde{n}^{+}>1$. If future fertility were to decline sufficiently due to changes in tastes or if $\alpha / \lambda$ were to fall sufficiently, then $\tilde{n}^{+}$could fall below one. Emissions growth without a cap would then become negative and the emissions problem would vanish over time.
} 
$y_{t}^{*} \equiv\left(1-\tilde{\psi} \tilde{n}_{t}^{*}\right) f\left(\tilde{e}_{t}^{*}\right) \lambda^{t}$. In the calibrations below we eliminate the growth factor by reporting optimal taxes as shares of income

$$
\{\tau / y\}_{t}^{*} \equiv \frac{\tau_{t}^{*}}{y_{t}^{*}}=\frac{\tilde{\tau}_{t}^{*} \lambda / \alpha}{\left(1-\tilde{\psi} \tilde{n}_{t}^{*}\right) f\left(\tilde{e}_{t}^{*}\right)} .
$$

\section{Calibrations}

To assess the magnitude of the population externality, we calibrate the model to a growth-adjusted economy with annual steady-state population growth of 1.4 percent, per-capita output growth of 1.7 percent, and aggregate emissions growth of 1.8 percent, which were actual world growth rates over 1990-2005. ${ }^{24}$ We take a period to equal 30 years. Thus $n^{+}=1.52, \tilde{n}^{+}=n^{+} \lambda / \alpha=1.72$, $\alpha=1.48$, and $\lambda=1.67 .{ }^{25}$ The value of $b_{0}$ is chosen so the household's firstorder condition holds given these three growth rates. We choose units so $\tilde{e}^{+}=1$, $f(1)=1$, and $\tilde{N}_{0}=1$.

We consider two simple production functions. ${ }^{26}$ One, which we refer to as Cobb-Douglas, is

$$
f(\tilde{e})=f_{0} \tilde{e}^{f_{1}}\left(f_{2}-\tilde{e}\right)^{1-f_{1}}
$$

where $f_{0}, f_{1} \in(0,1)$, and $f_{2}$ are parameters. Under (35), the factor share of emissions rises monotonically and approaches $f_{1}$ as $\tilde{e}$ declines to zero. Note that (35) may be derived from three primitive assumptions: $(i)$ each unit of labor is used to produce two intermediate goods in amounts $y_{1}$ and $y_{2}$ according to the linear technology $y_{1}+y_{2}=f_{2} ;(i i)$ a unit of intermediate good 1 generates a unit of emissions so $\tilde{e}=y_{1}$, whereas intermediate good 2 generates no emissions; and (iii) output per unit of labor is a Cobb-Douglas function $f_{0} y_{1}^{f_{1}} y_{2}^{1-f_{1}} \cdot{ }^{27}$

For any $f_{1}$, units choices pin down $f_{0}$ and $f_{2}$ : $\tilde{e}^{+}=1$ implies $f^{\prime}(1)=0$ so $f_{2}=1 / f_{1}$; and this plus $f(1)=1$ implies $f_{0}=\left[f_{1} /\left(1-f_{1}\right)\right]^{1-f_{1}}$. To set $f_{1}$, we assume it costs 3 percent of output to reduce emissions by 25 percent, so $f(0.75)=0.97$. This implies $f_{1}=0.483$. A 3 -percent cost is in the range of estimates in Stern (2007). We also evaluate a 2-percent cost below, which implies $f_{1}=0.371$.

\footnotetext{
${ }^{24}$ see World Resources Institute (2008).

${ }^{25}$ Specifically $n^{+}=\exp (30 \cdot .014)=1.52$. From section VI, per-capita income grows with factor $\lambda$ so $\lambda=\exp (30 \cdot .017)=1.67$. Also, total emissions grow at the same rate as productivity-adjusted population, so $\tilde{n}^{+}=n^{+} \lambda / \alpha=\exp (30 \cdot .018)=1.72$. This implies $\alpha=n^{+} \lambda / \tilde{n}^{+}=1.48$.

${ }^{26} \mathrm{~A}$ more general approach would be to start with assumptions about values of $f$ at a number of values of $\tilde{e}$, and then use spline interpolations to approximate $f$ over $[0,1]$. This alternative approach would require dealing with technical issues not central to the current paper, such as ensuring appropriate limit behavior at $\tilde{e}=0$ and $\tilde{e}=1$, and ensuring sufficient continuity of derivatives of $f$.

${ }^{27}$ The Cobb-Douglas form matters. If output per unit of labor were a CES function of $y_{1}$ and $y_{2}$ with an elasticity other than one, the factor share of emissions would approach either zero or one as $\tilde{e} \rightarrow 0$, which may be undesirable to impose.
} 
The Cobb-Douglas production function does not allow for a positive backstop. To study cases with a backstop and to get a sense of how sensitive the results are to the assumed form of the production function, we also consider cases with the abatement-cost specification used in many integrated assessment models,

$$
f(\tilde{e})=1-\left(1-g_{0}\right)(1-\tilde{e})^{g_{1}},
$$

where $g_{0}$ and $g_{1}$ are parameters and the backstop output level is $f(0)=g_{0}$. An interpretation of (36) is that a unit of labor gives a unit of output along with a unit emissions if no resources are devoted to abatement, and that the cost of abating $1-\tilde{e}$ units of emissions is $\left(1-g_{0}\right)(1-\tilde{e})^{g_{1}}$ units of output. $^{28}$

When we use the abatement-cost specification without a backstop, we set $g_{0}=0$ and set $g_{1}$ by again assuming it costs 3 percent of output to reduce emissions by 25 percent, so $g_{1}=3.32$. When we consider positive backstops, we leave the curvature $g_{1}$ unchanged and simply assume positive values of $g_{0}$, which proportionately reduces abatement costs at any $\tilde{e}$.

We assume children have an output cost of $\chi=0.138$ and a time cost of $\psi=0.110$. Details are in the appendix. Briefly, the output cost is obtained from the sum of expenditures by families on children and expenditures on K-12 and college education. The time cost is obtained by assuming the difference between male and female labor-force participation rates is due solely to time devoted to having children so that with zero children, the average participation rate would equal the current male participation rate (0.76) instead of the current average of male and female participation rates (0.685). The time cost implies that percapita labor in the uncapped economy is $1-\psi \tilde{n}^{+}=0.833$, so per-capita income is $\tilde{y}^{+}=\left(1-\tilde{\psi} \tilde{n}^{+}\right) f\left(e^{+}\right)=0.833$.

\section{A. Baseline}

We first study a baseline calibration with Cobb-Douglas production and Barro-Becker utility with $\theta=b=0.8 .^{29}$ The value of $\theta$ is in the range implied by estimates of the elasticity of intertemporal substitution in consumption. ${ }^{30}$ The assumption that $\theta=b$ follows Jones and Schoonbroodt (2007) and Jones et al. (2008). Note that the utility a parent gets from the consumption of children is $\beta(n) u(c)=\frac{b_{0}}{1-\theta}\left[n c^{\frac{1-\theta}{1-b}}\right]^{1-b}$ where $\frac{1-\theta}{1-b}$ is the relative weight placed on per-child

\footnotetext{
${ }^{28}$ The factor share of emissions under the abatement-cost specification has a knife-edge, which partly motivates why we use Cobb-Douglas for most calibrations. Namely, without a backstop, the factor share rises monotonically from zero at $\tilde{e}=1$ to one at $\tilde{e}=0$, but with any positive backstop, the factor share rises from zero at $\tilde{e}=1$ to a peak at an interior value of $\tilde{e}$, then falls to zero at $\tilde{e}=0$.

${ }^{29}$ The numerical procedures are described in the appendix.

${ }^{30}$ The parameter $\theta$ is the inverse of the (dynastic) elasticity of intertemporal substitution in consumption. Values of the (non-dynastic) elasticity of intertemporal substitution have been estimated using different approaches and data; a reasonable range of implied (non-dynastic) $\theta$-values might be 0.5-5.0 - see e.g. Ogaki and Reinhardt (1998), Bansal and Yaron (2004).
} 
consumption as opposed to the number of children. Values $\frac{1-\theta}{1-b} \approx 1$, or $\theta \approx b$, seem reasonable. ${ }^{31}$

Because population is normalized to $\tilde{N}_{0}=1$ in the transition period and percapita labor before a cap is imposed is 0.833 , emissions at $t=0$ would be 0.833 without a cap. In most calibrations we assume emissions are frozen at $t=0$ so $\hat{E}=0.833$. Steady-state emissions ratios and per-capita incomes are invariant to $\hat{E}$, but steady-state natural and optimal populations, $\tilde{N}_{s s}=\frac{\hat{E}}{(1-\tilde{\psi}) \tilde{e}_{s s}}$ and $\tilde{N}_{s s}^{*}=\frac{\hat{E}}{(1-\tilde{\psi}) \tilde{e}_{s s}^{*}}$, are proportional to $\hat{E}$.

Steady-state results for the baseline are in the first two rows of table 1 . The growth-adjusted steady-state natural population is $\tilde{N}_{s s}=9.16$, which is 9.16 times $\tilde{N}_{0}$. The steady-state emissions ratio is 0.101 times the emissions ratio without a cap. The reduced emissions imply substantial impoverishment: percapita output falls from $\tilde{y}^{+}=0.833$ before a cap is imposed to $\tilde{y}_{s s}=0.408$ in the natural steady state.

Figure 4 -- Results
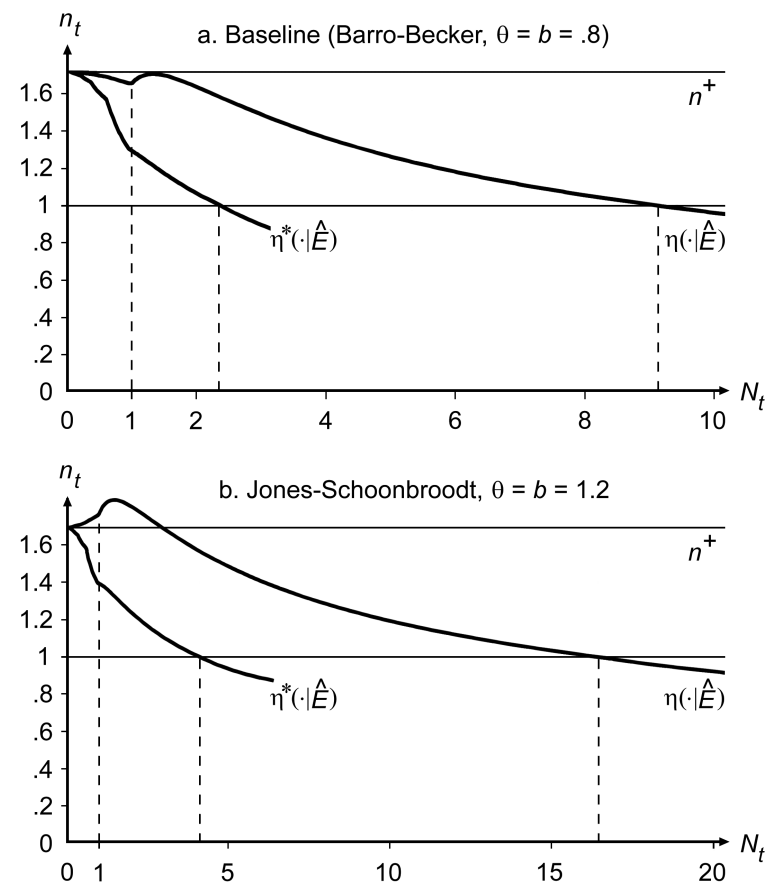

The growth-adjusted optimal population in steady state under a cap is 2.39 times the growth-adjusted population in the transition period. Thus in steady

\footnotetext{
${ }^{31}$ If the total consumption of all of a parent's children, $n c$, is an economic resource for the parent and the parent's fertility choices reflect care about this resource, then parents may be modelled as maximizing $n c$. When $\theta=b$, the term $\beta(n) u(c)$ depends on precisely $n c$.
} 
state, the natural population is almost four $(9.16 / 2.39)$ times the optimal population. The optimal emissions ratio is higher than the natural emissions ratio in steady state and equals 0.386 times the uncapped ratio. Accordingly, percapita optimal output, 0.721, exceeds per-capita natural output and is 13.5 percent below uncapped output.

The equilibrium fertility functions (figure 4a) imply that the natural and optimal populations converge smoothly from $\tilde{N}_{0}=1$ to steady-state values. After five generations, the growth-adjusted natural population is $\tilde{N}_{5}=6.84$, for instance, and after ten generations it is $\tilde{N}_{10}=8.97$, not far from the steady-state value of 9.16 .

Figure 5 shows the actual natural and optimal populations in the baseline. Without a cap, population increases exponentially. With a cap in steady state, the natural and optimal populations grows at rate $(\alpha-\lambda) / \lambda=-0.113$ under the parametrizing assumptions here, so both actual populations peak after a cap is imposed and then fall.

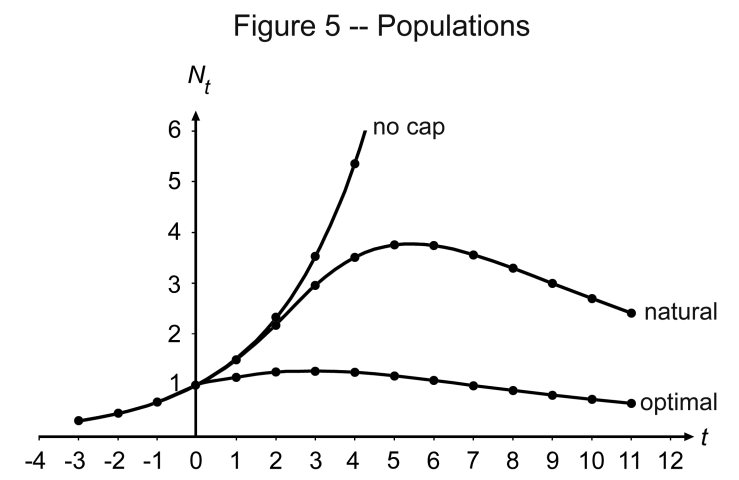

Turning to fiscal variables, a cap yields auction revenue equal to 45.7 percent of output in the natural steady state and 36.5 percent of output in the optimal steady state. These numbers are large given that the Federal spending share over 1990-2005 averaged about 20 percent of output. Emissions revenues are large because a cap leads to relatively great impoverishment in steady state. Emissions revenue is smaller right after the cap is imposed but increases sharply as the emissions ratio falls below one. For a freeze, for instance, revenue jumps from 0.7 percent of output at $t=0$ to 27.1 percent of output at $t=1$.

The optimal child tax in steady state is 21.1 percent of per-capita income. ${ }^{32}$ To get a sense of this, personal income in the U.S. is (very) roughly $\$ 55,000$ per adult per year, which may be interpreted as uncapped income $\left(\tilde{y}^{+}\right)$measured in dollars per year (converted from units of output per efficiency unit of labor per generation). Steady-state optimal income $\left(\tilde{y}_{s s}^{*}\right)$, which is 13.5 percent less than uncapped income, would then be about $\$ 48,000$. Thus a child tax of 21.1

\footnotetext{
${ }^{32}$ Income excludes redistributions of child-tax revenue, so a tax of 21.1 percent of income is equivalent to a tax of $17.4(=21.1 / 1.211)$ percent of income plus redistributions of child-tax revenue.
} 
percent is equivalent to a tax of about $\$ 10,000$ each year for 30 years (the length of a generation in the model) for each child. ${ }^{33}$ An alternative sense is that the annual cost of a child is about $\$ 13,000$ (of which about $\$ 6,000$ is time costs). The optimal child tax therefore raises the full cost of a child in steady state by about three-quarters, from $\$ 13,000$ to $\$ 23,000$, to just under one-half $(\$ 23,000 / \$ 48,000)$ of income.

The time path of the optimal child tax for a freeze is in table 2, row 1. At $t=0$, for instance, the tax is 5.2 percent of income, and at $t=1$, it is 11.6 percent of income, a bit more than one-half of the steady-state value. The tax path following an emissions cut is generally higher than following a freeze. The optimal child tax for a 25 percent cut $(\hat{E}=0.62)$, for instance, is 12.2 percent of income at $t=0$ and 15.5 percent of income at $t=1$. (Optimal tax sequences converge to the same steady-state tax rate regardless of $\hat{E}$.)

\section{B. Sensitivity Analysis-Utility}

In rows three and four of table 1 , we report steady-state values for a JonesSchoonbroodt case with $\theta=b=1.25$. (All sensitivity analyses change one assumption from the baseline.) As noted in section III, a value $\theta>1$ means that reduced children's utility under a cap leads parents to increase fertility. This causes a fertility burst after a cap is imposed (figure $4 \mathrm{~b}$ ) relative to the Barro-Becker case, driving up the steady-state natural population to 17.0 times the transition-period population. As a result, the optimal child tax is higher than in the baseline, equalling 36.3 percent of income in steady state. Along the transition path, the optimal child tax for a freeze is 7.0 percent of income at $t=0$ and 15.8 percent of income at $t=1$. The ratio of the natural to optimal steady-state populations $\tilde{N}_{s s} / \tilde{N}_{s s}^{*}$ is about four, as in the baseline.

The different shapes of the fertility functions in the Barro-Becker and JonesSchoonbroodt cases (figures $4 \mathrm{a}$ and $4 \mathrm{~b}$ ) arise because a greater value of $\theta=b$, operating through children's utility, makes equilibrium fertility less responsive to income. Because population drives income, fertility is therefore less responsive to population when $\theta=b$ is high. Assuming a greater $\theta=b$ may make sense if one believes fertility is not very sensitive to economic variables. In the current context, this is a pessimistic assumption: steady-state population, impoverishment, and optimal child taxes can be quite large if $\theta=b$ is great. For instance, rows five and six of table 1 show the steady state for a more extreme Jones-Schoonbroodt case with $\theta=b=2$. In this case the steady-state natural population is 44.1 times the transition-period population, and steady-state income is $\tilde{y}_{s s}=0.195$. Lower income means a larger $f^{\prime}$ and hence a larger pop-

\footnotetext{
${ }^{33}$ Kelly and Kolstad (2001) calculate welfare costs from a marginal child in the range $\$ 200$ $\$ 800$. Such costs are tiny compared with costs of $\$ 10,000$ per year for 30 years. Kelly and Kolstad implicitly assume a backstop output of $f(0)=.93$ and also assume that population grows at an exogenously given rate that itself decreases at an exogenously given rate. With their production function in our model, the optimal policy would be to drive the emissions ratio to zero in steady state. This does not happen in their calculations because they assume growth slows enough so the backstop is never reached.
} 
ulation externality; the optimal steady-state child tax is 95.7 percent of income when $\theta=b=2 .{ }^{34}$ The ratio of the natural to optimal steady-state populations $\tilde{N}_{s s} / \tilde{N}_{s s}^{*}$ is again about four.

The optimal child tax is smaller the lower the value of $\theta=b$. With low enough $\theta=b$, fertility would respond very elastically to changes in population so a cap would act like a switch that turns off fertility, and the optimal child tax could be quite small. To examine whether this occurs with plausible parameter values, we consider a Barro-Becker case with $\theta=b=0.4$. (Steady-state details are in the appendix.) The resulting $\tilde{N}_{s s}$ is still 4.97 times the transition population (and $\tilde{N}_{s s}^{*}=1.43$ so $\tilde{N}_{s s} / \tilde{N}_{s s}^{*}=3.47$ ), and the optimal steady-state child tax is still 10.7 percent of income. To obtain Pigovian taxes below 10 percent, one would have to assume even lower values of $\theta=b$.

We also examined how results change when $\theta \neq b$ so $\frac{1-\theta}{1-b}$ deviates from one. Holding $b=0.8$ constant, $\frac{1-\theta}{1-b}=0.8$ implies a steady-state natural population that is 9.36 times the transition-period population and an optimal steady-state child tax that is 18.7 percent of income. (Steady-state details are in the appendix.) When $\frac{1-\theta}{1-b}=1.25$, the steady-state natural population is 8.91 times the transition-period population and the optimal steady-state child tax is 22.4 percent of income. Thus moderate deviations of $\frac{1-\theta}{1-b}$ from one yield results close to baseline results.

\section{Sensitivity Analysis-Technology}

There is debate about the true cost of reducing emissions. To evaluate the importance of cost assumptions, rows seven and eight of table 1 report steadystate results when $f$ is parameterized by assuming it costs 2 percent of output to reduce emissions by 25 percent $(f(0.75)=0.98)$, instead of 3 percent as in the baseline.

Resulting steady-state natural income is slightly higher than in the baseline, 0.418 instead of 0.408 , but steady-state optimal income is lower, 0.665 instead of 0.721 . The difference between $\tilde{y}_{s s}^{*}$ and $\tilde{y}_{s s}$ declines because lower costs of reducing emissions mean the externality term $f^{\prime}(e) e$ in (22) is lower. Accordingly, the optimal child tax falls from 21.1 percent in the baseline to 18.0 percent with the lower cost of reducing emissions. Note however that steady-state emission ratios are much reduced: $\tilde{e}_{s s}$ is only 0.059 instead of 0.101 in the baseline; and $\tilde{e}_{s s}^{*}$ is 0.233 instead of 0.386 . Consequently, $\tilde{N}_{s s}$ and $\tilde{N}_{s s}^{*}$ are roughly two-thirds greater than in the baseline but their ratio remains about four. Intuitively, when it is less costly to reduce emissions, incomes and hence fertility are higher at any given population, and steady state is reached only when populations are so high and emissions ratios so low that incomes are at levels similar to incomes in the baseline.

Finally, we consider the abatement-cost specification (36) with backstop production levels of $0,0.2,0.4$, and 0.6 . Table 3 describes resulting steady states.

\footnotetext{
${ }^{34}$ This is equivalent to a tax of $48.9(=95.7 / 1.957)$ percent of income plus redistributions of child-tax revenue.
} 
To start, comparison of the first two rows of the table with the first two rows of table 1 shows the effects of changing from a Cobb-Douglas to an abatement-cost specification with no backstop. Steady-state natural and optimal populations fall by a bit less than one-half and factor shares of emissions rise, but optimal child taxes change relatively little, rising from 21.1 percent to 24.9 percent of income. Comparing rows of table 3, we see that as the assumed value of the backstop rises, impoverishment as well as population externalities are reduced, so steady-state populations rise and optimal taxes fall.

Under baseline utility assumptions, the critical value of the backstop output level is $f^{B}=0.507$. Thus for all production functions with $f(0)<0.507$, the natural economy converges to a steady state with constant (growth-adjusted) population, and for production functions with $f(0)>0.507$, the economy converges to the backstop at $\tilde{e}=0$ and population increases forever. Although these long-term outcomes differ greatly, the paths of the economy for the first few periods after transition are similar. We illustrate this by reporting in table 2 the time paths of the optimal child tax for different production functions. Under the abatement-cost specification with $f(0)=0.6$, for instance, abatement costs at any $\tilde{e}$ are reduced by 60 percent compared with abatement costs with $f(0)=0$. The tax as a share of income in the transition period when $f(0)=0.6$ is similarly about one-half of the tax share when $f(0)=0$. When $f(0)=0.6$, the tax share peaks in the third period after transition but is still about one-half of the share in the baseline, then approaches zero in steady state. ${ }^{35}$

From table 3, the ratio of the natural to the optimal steady-state populations varies between about three and five for the cases with $f(0)<0.507$. In the effective-backstop case with $f(0)=0.6$, both $\tilde{N}_{s s}$ and $\tilde{N}_{s s}^{*}$ go to infinity but their ratio converges to about 3.4.

\section{Conclusion}

In Malthus, consumption tends to subsistence and total population tends to a constant. In Solow-type neoclassical growth models, additional population produces additional output under constant returns so total population can rise without bound. In the current paper, output is produced from labor and a fixed environmental resource, total emissions, which is sometimes essential in that output per unit of labor falls to zero as the ratio of emissions to labor falls to zero. Then constant returns instead implies that total population is limited: as population and hence labor grow, the relative amount of the fixed factor falls, which drives down per-capita output and limits population growth.

This logic relies on changes in factor ratios as population grows and is independent of the name of the fixed resource. If land is fixed, greater population raises the ratio of labor to land. If land were also assumed to be essential,

\footnotetext{
${ }^{35}$ Population growth remains positive when $f(0)=.6$ as the emissions ratio converges to zero: $\tilde{n}_{t}$ converges to 1.16 and population growth $n_{t}=\tilde{n}_{t}(\alpha / \lambda)$ converges to 1.03 . In the limit, $n_{t}^{*}$ converges to the same limit of 1.03. This is substantially lower than population growth of $n^{+}=1.52$ in the uncapped economy.
} 
overcrowding would ultimately drive down per-capita output enough to choke off population growth, unless productivity also were to grow over time.

The result that population converges to a steady-state constant is modified in the presence of exogenous factor-augmenting productivity growth. Then the growth-adjusted population converges a steady-state constant, which means the actual population has a growth factor that converges to the growth factor for emissions productivity divided by the growth factor for labor productivity. Because actual per-capita emissions have been rising, this ratio of growth factors currently appears to be less than one. In steady state, a ratio less than one means the actual and optimal populations decrease over time.

The focus of the current paper is on the population externality induced by a cap that fixes total emissions. A robust finding is that this externality is substantial under reasonable assumptions. ${ }^{36}$ In our baseline calibration, for instance, the optimal Pigovian tax on each child is about 20 percent of income, and the Pigovian tax is higher in some other calibrations. Similarly, the steadystate natural population is about four times the steady-state optimal population in the baseline, and ranges between about three and five times the optimal population in other calibrations.

\footnotetext{
${ }^{36}$ The analysis identifies four circumstances under which the population externality induced by a cap might not be large: if marginal utilities fall off very slowly (utility curvatures $\theta$ and $b$ are small) so imposition of a cap by itself would rapidly turn off population growth; if $\theta$ and $b$ differ greatly and $\theta>b$; if the output cost of eliminating all emissions is small; or if fertility and productivity trends change so global emissions decline on their own without policy intervention. There appears to be little empirical support for any of these.
} 


\section{References}

${ }^{1}$ Bansal, Ravi and Amir Yaron, "Risks for the Long Run: A Potential Resolution of Asset Pricing Puzzles," Journal of Finance, 69, No. 4, Aug. 2004, 1481-1509.

${ }^{2}$ Barro, Robert and Gary Becker, "A Reformulation of the Economic Theory of Fertility," Quarterly Journal of Economics, 103, No. 1, Feb. 1988, 1-25.

3 __ "Fertility Choice in a Model of Economic Growth," Econometrica, 57, No. 2, Mar. 1989, 481-501.

${ }^{4}$ Becker, Gary, "An Economic Analysis of Fertility," in Demographic and Economic Change in Developed Countries, Princeton: Princeton University Press, 1960.

${ }^{5}$ Bovenberg, A. Lans, and Lawrence Goulder, "Optimal Environmental Taxation in the Presence of Other Taxes: General-Equilibrium Analyses," American Economic Review, 86, No. 4, Sept. 1996, 985-1000.

${ }^{6}$ Harford, Jon, "The Ultimate Externality," American Economic Review, 88, No. 1, Mar. 1998, 260-65.

${ }^{7}$ Jones, Larry, and Alice Schoonbroodt, "Complements versus Substitutes and Trends in Fertility Choice in Dynastic Economies," NBER working paper 13680, 2007.

${ }^{8}$ Jones, Larry, Alice Schoonbroodt, and Michèle Tertilt, "Fertility Theories: Can They Explain the Negative Fertility-Income Relationship," NBER working paper 14266, 2008.

${ }^{9}$ Kelly, David and Charles Kolstad, "Bayesian Learning, Growth, and Pollution," Journal of Economic Dynamics and Control, 23, No. 4, Feb. 1999, 491-518.

$10 \_$__ "Malthus and Climate Change: Betting on Stable Population," Journal of Environmental Economics and Management, 41, No. 2, Mar. 2001, 135-61.

${ }^{11}$ Mendelsohn, R.O., W.N. Morrison, M.E. Schlesinger, and N.G. Andronova, "Country-Specific Market Impacts of Climate Change," Climatic Change 45, No.3-4, 1998, 553-569.

${ }^{12}$ Nordhaus, William and J.G. Boyer, Warming the World: the Economics of the Greenhouse Effect, Cambridge, MA: MIT Press, 2000.

${ }^{13}$ Ogaki, Masao and Carmen Reinhart, "Measuring Intertemporal Substitution: The Role of Durable Goods," Journal of Political Economy, 103, No. 3, Oct. 1998, 1078-98. 
${ }^{14}$ Stern, Nicholas, Economics of Climate Change: The Stern Review, Cambridge: Cambridge University Press, 2007.

${ }^{15}$ World Resources Institute, Climate Analysis Indicators Tool (CAIT), version 3.0., Washington, DC: World Resources Institute, http://cait.wri.org, 2008. 
Table 1. Steady States

\begin{tabular}{ccccccc} 
Case & Regime & $\tilde{N}_{s s}$ & $\tilde{e}_{s s}$ & $\tilde{y}_{s s}$ & $f^{\prime} \tilde{e} / f$ & $\{\tau / y\}_{s s}^{*}$ \\
\hline \multirow{2}{*}{ Barro-Becker (baseline, $\theta=b=.8)$} & natural & 9.16 & .101 & .408 & .457 & \\
& optimal & 2.39 & .386 & .721 & .365 & .211 \\
Jones-Schoonbroodt, $\theta=b=1.25$ & natural & 17.0 & .054 & .306 & .469 & \\
& optimal & 4.26 & .216 & .572 & .423 & .363 \\
Jones-Schoonbroodt, $\theta=b=2$ & natural & 44.1 & .021 & .195 & .469 & \\
& optimal & 11.1 & .083 & .373 & .478 & .957 \\
2 percent cost of $\tilde{e}=.75$ & natural & 15.6 & .059 & .418 & .357 & \\
& optimal & 3.96 & .233 & .665 & .311 & .180 \\
\hline
\end{tabular}

Table 2. Time Paths of Optimal Child Taxes

\begin{tabular}{ccccccc} 
Case & $\{\tau / y\}_{0}^{*}$ & $\{\tau / y\}_{1}^{*}$ & $\{\tau / y\}_{2}^{*}$ & $\{\tau / y\}_{3}^{*}$ & $\{\tau / y\}_{4}^{*}$ & $\{\tau / y\}_{s s}^{*}$ \\
\hline baseline, Cobb-Douglas & .052 & .116 & .152 & .174 & .199 & .211 \\
abatement cost, $f(0)=0$ & .055 & .141 & .195 & .223 & .237 & .249 \\
abatement cost, $f(0)=.2$ & .047 & .124 & .174 & .203 & .219 & .237 \\
abatement cost, $f(0)=.4$ & .037 & .101 & .142 & .166 & .179 & .201 \\
abatement cost, $f(0)=.6$ & .026 & .079 & .093 & .100 & .098 & 0 \\
\hline
\end{tabular}

Table 3. Steady States with Abatement-Cost Production at Different Backstops

\begin{tabular}{ccccccc} 
Case & Regime & $\tilde{N}_{s s}$ & $\tilde{e}_{s s}$ & $\tilde{y}_{s s}$ & $f^{\prime} \tilde{e} / f$ & $\{\tau / y\}_{s s}^{*}$ \\
\hline \multirow{2}{*}{$f(0)=0$} & natural & 4.84 & .190 & .374 & .842 & \\
& optimal & 1.58 & .586 & .805 & .431 & .249 \\
$f(0)=.2$ & natural & 6.75 & .137 & .405 & .493 & \\
& optimal & 1.86 & .497 & .775 & .409 & .237 \\
$f(0)=.4$ & natural & 15.6 & .059 & .438 & .168 & \\
& optimal & 2.84 & .325 & .702 & .348 & .201 \\
$f(0)=.6$ & natural & $\infty$ & 0 & .532 & 0 & \\
& optimal & $\infty$ & 0 & .532 & 0 & 0 \\
\hline
\end{tabular}




\section{CESifo Working Paper Series}

for full list see www.cesifo-group.org/wp

(address: Poschingerstr. 5, 81679 Munich, Germany, office@cesifo.de)

2981 Frederick van der Ploeg, Rapacious Resource Depletion, Excessive Investment and Insecure Property Rights, March 2010

2982 Wolfram F. Richter and Christoph Braun, Efficient Subsidization of Human Capital Accumulation with Overlapping Generations and Endogenous Growth, March 2010

2983 Francesco Cinnirella, Marc Piopiunik and Joachim Winter, Why Does Height Matter for Educational Attainment? Evidence from German Pre-Teen Children, March 2010

2984 Bernard Van Praag, Well-being Inequality and Reference Groups - An Agenda for New Research, March 2010

2985 Francesca Barion, Raffaele Miniaci, Paolo M. Panteghini and Maria Laura Parisi, Profit Shifting by Debt Financing in Europe, March 2010

2986 Alexander Haupt and Magdalena Stadejek, The Choice of Environmental Policy Instruments: Energy Efficiency and Redistribution, March 2010

2987 John Komlos and Marek Brabec, The Trend of BMI Values among US Adults, March 2010

2988 Emanuele Massetti and Lea Nicita, The Optimal Climate Policy Portfolio when Knowledge Spills across Sectors, March 2010

2989 Helmut Rainer and Thomas Siedler, Family Location and Caregiving Patterns from an International Perspective, March 2010

2990 Toru Kikuchi and Ngo Van Long, A Simple Model of Service Offshoring with Time Zone Differences, March 2010

2991 Assaf Razin, Efraim Sadka and Benjarong Suwankiri, Migration and the Welfare State: Dynamic Political-Economy Theory, March 2010

2992 Bård Harstad, Buy Coal! Deposit Markets Prevent Carbon Leakage, March 2010

2993 Axel Dreher, Stephan Klasen, James Raymond Vreeland and Eric Werker, The Costs of Favoritism: Is Politically-driven Aid less Effective?, March 2010

2994 Sven Neelsen and Thomas Stratmann, Effects of Prenatal and Early Life Malnutrition: Evidence from the Greek Famine, March 2010

2995 Claude Hillinger and Bernd Süssmuth, The Quantity Theory of Money: An Assessment of its Real Linchpin Prediction, March 2010 
2996 Matthew M. Chingos and Martin R. West, Do More Effective Teachers Earn More Outside of the Classroom?, March 2010

2997 Laurence Jacquet and Dirk Van de gaer, A Comparison of Optimal Tax Policies when Compensation or Responsibility Matter, March 2010

2998 Valentina Bosetti, Carlo Carraro, Romain Duval and Massimo Tavoni, What Should we Expect from Innovation? A Model-Based Assessment of the Environmental and Mitigation Cost Implications of Climate-Related R\&D, March 2010

2999 Scott Alan Carson, Nineteenth Century Stature and Family Size: Binding Constraint or Productive Labor Force?, March 2010

3000 Jukka Pirttilä and Ilpo Suoniemi, Public Provision, Commodity Demand and Hours of Work: An Empirical Analysis, March 2010

3001 Bertrand Candelon and Franz C. Palm, Banking and Debt Crises in Europe: The Dangerous Liaisons?, March 2010

3002 Joan Costa-i-Font and Marin Gemmill-Toyama, Does Cost Sharing really Reduce Inappropriate Prescriptions?, March 2010

3003 Scott Barrett, Climate Treaties and Backstop Technologies, March 2010

3004 Hans Jarle Kind, Tore Nilssen and Lars Sørgard, Price Coordination in Two-Sided Markets: Competition in the TV Industry, March 2010

3005 Jay Pil Choi and Heiko Gerlach, Global Cartels, Leniency Programs and International Antitrust Cooperation, March 2010

3006 Aneta Hryckiewicz and Oskar Kowalewski, Why do Foreign Banks Withdraw from other Countries? A Panel Data Analysis, March 2010

3007 Eric A. Hanushek and Ludger Woessmann, Sample Selectivity and the Validity of International Student Achievement Tests in Economic Research, March 2010

3008 Dennis Novy, International Trade and Monopolistic Competition without CES: Estimating Translog Gravity, April 2010

3009 Yin-Wong Cheung, Guonan Ma and Robert N. McCauley, Renminbising China's Foreign Assets, April 2010

3010 Michel Beine and Sara Salomone, Migration and Networks: Does Education Matter more than Gender?, April 2010

3011 Friedrich Schneider, Tilman Brück and Daniel Meierrieks, The Economics of Terrorism and Counter-Terrorism: A Survey (Part I), April 2010

3012 Friedrich Schneider, Tilman Brück and Daniel Meierrieks, The Economics of Terrorism and Counter-Terrorism: A Survey (Part II), April 2010 
3013 Frederick van der Ploeg and Steven Poelhekke, The Pungent Smell of "Red Herrings": Subsoil Assets, Rents, Volatility and the Resource Curse, April 2010

3014 Vjollca Sadiraj, Jan Tuinstra and Frans van Winden, Identification of Voters with Interest Groups Improves the Electoral Chances of the Challenger, April 2010

3015 Guglielmo Maria Caporale, Davide Ciferri and Alessandro Girardi, Time-Varying Spot and Futures Oil Price Dynamics, April 2010

3016 Scott Alan Carson, Racial Differences in Body-Mass Indices for Men Imprisoned in $19^{\text {th }}$ Century US Prisons: A Multinomial Approach, April 2010

3017 Alessandro Fedele, Paolo M. Panteghini and Sergio Vergalli, Optimal Investment and Financial Strategies under Tax Rate Uncertainty, April 2010

3018 Laurence Jacquet, Take it or Leave it: Take-up, Optimal Transfer Programs, and Monitoring, April 2010

3019 Wilhelm Kohler and Jens Wrona, Offshoring Tasks, yet Creating Jobs?, April 2010

3020 Paul De Grauwe, Top-Down versus Bottom-Up Macroeconomics, April 2010

3021 Karl Ove Aarbu, Demand Patterns for Treatment Insurance in Norway, April 2010

3022 Toke S. Aidt and Jayasri Dutta, Fiscal Federalism and Electoral Accountability, April 2010

3023 Bahram Pesaran and M. Hashem Pesaran, Conditional Volatility and Correlations of Weekly Returns and the VaR Analysis of 2008 Stock Market Crash, April 2010

3024 Stefan Buehler and Dennis L. Gärtner, Making Sense of Non-Binding Retail-Price Recommendations, April 2010

3025 Leonid V. Azarnert, Immigration, Fertility, and Human Capital: A Model of Economic Decline of the West, April 2010

3026 Christian Bayer and Klaus Wälde, Matching and Saving in Continuous Time: Theory and 3026-A Matching and Saving in Continuous Time: Proofs, April 2010

3027 Coen N. Teulings and Nick Zubanov, Is Economic Recovery a Myth? Robust Estimation of Impulse Responses, April 2010

3028 Clara Graziano and Annalisa Luporini, Optimal Delegation when the Large Shareholder has Multiple Tasks, April 2010

3029 Erik Snowberg and Justin Wolfers, Explaining the Favorite-Longshot Bias: Is it RiskLove or Misperceptions?, April 2010

3030 Doina Radulescu, The Effects of a Bonus Tax on Manager Compensation and Welfare, April 2010 
3031 Helmut Lütkepohl, Forecasting Nonlinear Aggregates and Aggregates with Timevarying Weights, April 2010

3032 Silvia Rocha-Akis and Ronnie Schöb, Welfare Policy in the Presence of Unionised Labour and Internationally Mobile Firms, April 2010

3033 Steven Brakman, Robert Inklaar and Charles van Marrewijk, Structural Change in OECD Comparative Advantage, April 2010

3034 Dirk Schindler and Guttorm Schjelderup, Multinationals, Minority Ownership and TaxEfficient Financing Structures, April 2010

3035 Christian Lessmann and Gunther Markwardt, Decentralization and Foreign Aid Effectiveness: Do Aid Modality and Federal Design Matter in Poverty Alleviation?, April 2010

3036 Eva Deuchert and Conny Wunsch, Evaluating Nationwide Health Interventions when Standard Before-After Doesn't Work: Malawi's ITN Distribution Program, April 2010

3037 Eric A. Hanushek and Ludger Woessmann, The Economics of International Differences in Educational Achievement, April 2010

3038 Frederick van der Ploeg, Aggressive Oil Extraction and Precautionary Saving: Coping with Volatility, April 2010

3039 Ainura Uzagalieva, Evžen Kočenda and Antonio Menezes, Technological Imitation and Innovation in New European Union Markets, April 2010

3040 Nicolas Sauter, Jan Walliser and Joachim Winter, Tax Incentives, Bequest Motives, and the Demand for Life Insurance: Evidence from two Natural Experiments in Germany, April 2010

3041 Matthias Wrede, Multinational Capital Structure and Tax Competition, April 2010

3042 Burkhard Heer and Alfred Maussner, A Note on the Computation of the Equity Premium and the Market Value of Firm Equity, April 2010

3043 Kristiina Huttunen, Jukka Pirttilä and Roope Uusitalo, The Employment Effects of Low-Wage Subsidies, May 2010

3044 Matthias Kalkuhl and Ottmar Edenhofer, Prices vs. Quantities and the Intertemporal Dynamics of the Climate Rent, May 2010

3045 Bruno S. Frey and Lasse Steiner, Pay as you Go: A New Proposal for Museum Pricing, May 2010

3046 Henning Bohn and Charles Stuart, Population under a Cap on Greenhouse Gas Emissions, May 2010 